bioRxiv preprint doi: https://doi.org/10.1101/2021.09.27.462041; this version posted September 29, 2021. The copyright holder for this preprint (which was not certified by peer review) is the author/funder, who has granted bioRxiv a license to display the preprint in perpetuity. It is made available under aCC-BY-NC-ND 4.0 International license.

\title{
DIDO3 acts at the interface of RNAPII transcription and chromatin structure regulation
}

Tirso Pons ${ }^{1 \dagger}$, Francois Serra ${ }^{2 \dagger}$, Florencio Pazos ${ }^{3}$, Alfonso Valencia ${ }^{2,4}$, and Carlos Martínez-A ${ }^{1 *}$

1Department of Immunology and Oncology, Centro Nacional de Biotecnología (CNB-CSIC), 28049 Madrid, Spain

2Barcelona Supercomputing Center (BSC), 08034, Barcelona, Spain.

${ }^{3}$ Computational Systems Biology Group, Systems Biology Department, Centro Nacional de Biotecnología (CNBCSIC), 28049 Madrid, Spain

${ }^{4}$ ICREA, 08010, Barcelona, Spain.

† These authors contributed equally to this work

\begin{abstract}
Chromatin structure and organization has a key role in gene expression regulation. Here, we integrated ChIP-seq, RNA-seq, Hi-C, epigenetic, and cancer-related mutations data to get insight into the role of Death Inducer Obliterator gene (Dido1) in RNA pol II (RNAPII) transcription and chromatin structure regulation. Analysis of ChIP-seq data of DID03, the largest protein isoform of Dido1, revealed binding-sites overlap about $70 \%$ with RNAPII and H3K36me3 in the mouse genome, but also significant overlap 10-30\% with Polycomb, CTCF, H3K4me3, and H3K27ac. Based on this analysis we propose that DID03's PHD domain interacts with H3K36me3 posttranslational modification. Integrating multi-omics data we describe how DID03 potentially recruit several transcription factors, including RNAPII, and also regulates genes transcribing those same transcription factors. DID03 regulation of the genes traduced into proteins to which it binds puts DIDO3 in the center of intricate feedback loops. We showed, by using data from a DID03 mutant, that DID03 C-terminus is responsible for most of these transcriptional regulation, and is also implicated in other very important pathways by regulating genes encoding for Polycomb-accessory proteins, subunits of the SWI/SNF chromatin remodelling, or Set1/COMPASS chromatin modifier complexes. These multi-protein complexes control gene activation or silencing and also play a role in tumour development. DID03 C-terminus region and splice-site for alternative DID02/DID03 protein isoforms tended to accumulate recurrent truncating mutations identified in the TCGA Pan-Cancer dataset. We hypothesize that deregulation of DID03, as it happens with large epigenetic complexes and long-range interactions, leads to cell differentiation deficiency and cancer development. Overall, we propose here a molecular mechanism by which DID03, favour RNAPII pausing and long-range chromatin interactions.
\end{abstract}




\section{INTRODUCTION}

Death Inducer Obliterator (Dido1) is a complex gene expressed in all tissues (1) that encodes the three protein isoforms DID01, DID02 and DID03 (2). Previous bioinformatics analysis and experimental data revealed that these three protein isoforms have a common plant homeodomain (PHD) that binds to histone 3 trimethylated on lysine 4 (H3K4me3) $(3,4)$. DIDO2 and DIDO3 have a transcription elongation factor S II subunit M (TFSII_M) domain, which mediates binding to RNAPII $(3,5)$, and also have a SPOC domain characteristic of the Spen family proteins involved in transcriptional repression (6) (Figure 1). These three domains connect Dido1 to chromatinregulation processes; however, their contribution to cell differentiation and cancer remains to be elucidated.

In order to characterize DID03 function, and in particular its C-terminal, isoform specific, domain, Füttereret al. created a DID03 mutant with a deletion of its last exon, the sixteenth (DID03 $\Delta$ E16). They show that the mutation was lethal in early embryonic development $(7,8)$, embryos died by gestation day 8.5 . The same authors also showed that expressing DID03 $\triangle$ E16 mutant in embryonic stem cells (ESC) impeded cellular differentiation in vitro, but maintained their self-renewal capacity $(5,7,8)$. Both of these phenotypes, early embryonic lethality and in vitro loss of cellular differentiation were also observed altering other proteins linking them to DID03 function. $H 3 f 3 a$ and $H 3 f 3 b$ is a first example; their deletion causes embryonic lethality, in this case around day 6.5 (9), and defects in differentiation capacity (10-12). These genes encode for the H3.3 variant of the H3 core histone part of the nucleosome. The H3.3 is associated with chromatin dynamics and nucleosome turnover. H3.3 deposition is mediated by the histone regulator A (HIRA), a chaperone complex, that also associates H3.3 with the RNAPII machinery (13), transcription factors (TFs) (14), and replication protein A (15). Another example of phenotype similar to DID03 $3 \mathrm{E} 16$ has been observed after a homozygous gene deletion for COMPASS core subunits Ash2l and Dpy30, and PRC2 core subunits Eed and Suz12, with embryos dying by gestation day 8.5 (16). To be noted that, in this case, those nucleosome posttranslational modifications multiprotein complexes were not linked loss of differentiation in vitro.

As we said before, DIDO3 PHD domain preferentially binds to H3K4me3 (4). However, PHD domain also recognizes the peptide $\mathrm{H}_{1-20}$ with methylation and acetylation patterns at different positions (i.e., K4me $3+\mathrm{K} 9 \mathrm{ac}$, $\mathrm{K} 4 \mathrm{me} 3+\mathrm{K} 14 \mathrm{ac}, \mathrm{K} 4 \mathrm{me} 3+\mathrm{K} 18 \mathrm{ac}$ )(unpublished results communicated by T.G. Kutateladze et al). Although H3K4me3, H3K36me3, and H3K27ac marks are associated with genome activation (17), methylation patterns at H3K4 and H3K36 may cross talk with posttranslational modifications at H3K27 in the recruitment of PRC2; thus contributing to gene expression regulation and facultative heterochromatin establishment $(18,19)$. Detailed descriptions of H3K36me3 function in cryptic transcription, alternative pre-mRNA splicing, 3D chromosome organization and DNA damage response can be found elsewhere $(17,19)$. Nevertheless, affinity of binding of DID03's PHD domain to the peptide H321-44 with simultaneous methylation and acetylation patterns at K27 and K36 has not been tested.

An N-terminal truncation of Dido1 (Dido1 $\Delta \mathrm{NT}$ ), results in genomic instability, due to centrosome amplification and centromere localized DNA breaks (20,21), leading to myeloid malignancies (2). In the last years, several independent studies linked genetic alterations in Dido1 to different cancer types: Melanoma (22), Kaposiform hemangioendothelioma (23), Chronic Myeloid Leukemia (24), Prostate cancer (25), Head and neck cancer (26), Hepatic neuroendocrine tumours (27), Colorectal cancer (28), Bladder cancer (29), Renal cell carcinoma (30), and Esophageal cancer $(31,32)$. Some of these studies suggested an important role of epigenetic modifications and chromatin remodelling processes in cancer development. Interestingly, a cancer-related phenotype caused by centromere and kinetochore genes overexpression (e.g., Cenpa and its chaperone Hjurp, Cenpm) and protein mislocalization into noncentromeric regions, increases genome instability through centromere misregulation, increases levels of DNA damage, and correlates with poor patient prognosis $(33,34)$. However, the molecular details behind these associations and Dido1 disruption are not fully understood yet.

In the present work, we report that DIDO3 has a pleiotropic role in RNAPII transcription and chromatin structure regulation, presumably, mediated by participation in large protein complexes. There we underpin the role of DIDO3 chromosome instability in ESC self-renewal and differentiation, assembly of H3.3/CENP-A chaperone complexes, and chromatin structure regulation.

\section{MATERIALS AND METHODS}

\section{Software}

The following software was used in this study: ChIPseeker (35), clusterProfiler (36), and BEDTools (37) to analyse ChIP-seq data and generate binding site annotations; PyRanges (38) for comparison of genomic intervals; Networkx (39) to represent graphs; TADbit (40) to obtain chromatin three-dimensional interaction matrices, topologically associated domains (TADs) and A/B compartments from Hi-C experiments; Metascape (41) to provide a comprehensive gene list annotation, functional enrichment, and interactome analysis over 40 independent knowledge bases; Epicorr v1.20 (42) to find regions of the human genome epigenetically correlated 
with the Dido1 locus; and RStudio (www.rstudio.org) to run R/Bioconductor packages (e.g. org.Mm.eg.db, TxDb.Mmusculus.UCSC.mm10.knownGene, ggplot2, edgeR).

\section{Databases}

Cancer associated variants were retrieved from Pan-Cancer TCGA dataset using the cBioPortal tool (www.cbioportal.org) (43). We mined publicly available TCGA transcriptome data via the University of Alabama web portal (UALCAN; http://ualcan.path.uab.edu) (44). Protein codes and functional annotations were extracted from UniProtKB (www.uniprot.org) (45), Pfam (http://pfam.xfam.org/) (46), and PROSITE (https://prosite.expasy.org) (47).

\section{Data processing}

ChIP-seq data analysis. The genomic coordinates for HA-DID03 binding (GSE85029) were converted to the UCSC mouse genome build mm10 using liftOver (http://genome.ucsc.edu/cgi-bin/hgLiftOver). BED files were imported to RStudio and annotated using the R/Bioconductor package ChIPseeker (35). The promoter region was set to -1 $\mathrm{kb}$ to $200 \mathrm{bp}$ of the TSS. We also used the Bioconductor packages org.Mm.eg.db and TxDb.Mmusculus.UCSC.mm10.knownGene for peak annotations. Significance of overlap between ChIP-seq data sets was calculated using the enrichPeakOverlap function implemented in ChIPseeker, setting the number of random permutations (nShuffle) of the genomic locations to 10000. Genomic coordinates for the overlapped (or intersect) sites were calculated with the intersectBed function implemented in BEDTools (37). PyRanges (38) was also used for the comparison of genomic intervals.

RNA-seq and differential gene expression analysis. RNA-seq data for DIDO3 and DIDO3 E16 in mouse embryonic stem cells (GSE152346) and mouse embryonic fibroblasts (SRP150516 and PRJNA476070) were processed as described in (8). Briefly, Burrows-Wheeler aligner BWA-MEM 0.7.15 (http://bio-bwa.sourceforge.net) was used to align paired-end reads to the UCSC mouse genome build mm10 with standard settings. Alignments were converted to BAM format and de-duplicated with Picard tools 2.9.0 (http://broadinstitute.github.io/picard/). To quantify relative expression of transcripts, we ran StringTie 1.3.3 (48) and calculated the transcripts per million (TPM) reads. Sample scaling and statistical analyses were performed with the R package edgeR (49). Transcripts with TPM $>0$ in all samples were kept for downstream analysis. Differentially expressed genes with an absolute value of $\log 2$ fold change $\geq 0.7$ and a false-discovery rate (FDR) $<0.05$ were considered statistically significant.

Protein-protein interaction, gene ontology and pathway analysis. The complete list of genes with HA-DID03 binding sites detected in ChIP-seq, and those with gene expression alterations in RNA-seq data were submitted to Metascape (41) using the multi-gene-list and meta-analysis option. Metascape compiles protein interactions from BioGRID (https://thebiogrid.org) and provides a protein-protein interaction network along with sub-networks of highly connected proteins (modules) identified by the MCODE clustering algorithm. Gene ontology (50) and pathway enrichment analysis was also done with Metascape. The core set of default ontologies (i.e. GO processes, KEGG pathways, Reactome gene sets, canonical pathways, CORUM complexes) was applied for enrichment analysis. The hypergeometric test and Benjamini-Hochberg p-value correction algorithms were used by Metascape to identify all ontology terms that contain a statistically greater number of genes in common with the input list than expected by chance.

Hi-C data processing. All Hi-C data collected from GEO were first transformed to FASTQ files using parallel-fastqdump. Raw reads were processed with TADbit (40) for read quality control, read mapping, interaction detection, interaction filtering, and matrix normalization. Valid interactions were then used to generate genome-wide interaction maps at $100 \mathrm{~kb}, 50 \mathrm{~kb}, 20 \mathrm{~kb}$, and $5 \mathrm{~kb}$ to segment the genome into the so-called A/B compartments, TADs, and perform a meta-analysis, respectively. A/B compartments were calculated using normalized and decay corrected matrices by calculating the first component of a principal component analysis of chromosome-wide matrices of the Pearson product-moment internal correlation as described in (51) and implemented in TADbit (40). TADs were next identified at $50 \mathrm{~kb}$ resolution with the TAD border detection method implemented in TADbit (40). Chromatin loop were called using the Mustache software (52) run at $10 \mathrm{~kb}$ resolution with default parameters but lowering the sparsity threshold to 0.8 and increasing the p-value threshold to 0.5. Aggregate peak analysis (APA) consists of extracting small submatrices (here 21 by 21 cells at $5 \mathrm{~kb}$ resolution) from the genomic $\mathrm{Hi}-\mathrm{C}$ matrix at the intersection of a specific pair of genomic coordinates (53). Once the submatrices corresponding to all input pairs of genomic coordinates are extracted, these submatrices are averaged into a single APA. The interactions in this APA represent the average interactions between two lists of input coordinates. We then transformed the Cartesian coordinates of the APA into polar coordinates summing distance to the center in both Xand Y-axes (Figure 2E for an example between a list of coordinates of DIDO3 ChIP-seq peaks and a list of coordinates of H3K36me3 ChIP-seq peaks). The distance to the center in terms of number of $5 \mathrm{~kb}$ bins is then used to separate interaction cells in two categories, close to the center (less or equal to 5 bins), away from the center (the rest). The interactions in cells within these two categories were then compared using a T-test of independence in order to assess how strong is the interaction enrichment in the center. We interpret significant 
enrichment in the center of the APA as an indicator of tendency to colocalize in the nucleus, between the proteins or marks in the input lists of coordinates.

Computational analysis of epigenetically correlated regions. In order to look for regions of the human genome epigenetically correlated with Dido1 locus we used the epigenomic datasets compiled by the Roadmap Epigenomics Consortium (54). We downloaded the 127 "consolidated epigenomes", for which the chromatin states are given in a 15-state vocabulary for all 200 bp windows (https://egg2.wustl.edu/roadmap/web_portal/chr_state_learning.html). The 127 epigenomes include different tissues, embryonic stem cells, cancer cell lines, different developmental stages, etc. For these epigenomes, detailed information on different proxies of the epigenetic state is provided at a base-pair resolution, such as histone acetylation, DNA methylation, DNase accessibility or RNA-seq expression. For each 200bp genomic region, the ChromHMM method (55) is used to collapse all these experimental epigenetic proxies into a single "epigenetic state" with 15 possible values: Active TSS (TssA), Flanking Active TSS (TssAFlnk), Transcription at gene 5' and 3' (TxFlnk), Strong transcription (Tx), Weak transcription (TxWk), Genic enhancers (EnhG), Enhancers (Enh), ZNF genes \& repeats (ZNF/Rpts), Heterochromatin (Het), Bivalent/Poised TSS (TssBiv), Flanking Bivalent TSS/Enhancer (BivFlnk), Bivalent Enhancer (EnhBiv), Repressed PolyComb (ReprPC), Weak Repressed PolyComb (ReprPCWk), and Quiescent/Low (Quies). We downloaded from the URL above the BED files with these chromatin states for the 127 epigenomes. To work at lower resolutions (e.g. $1 \mathrm{~kb}$ window), the epigenetic state of a given window is taken as that with the highest frequency among the 200bp segments within the window; a minimum frequency of $80 \%$ is required otherwise, the undefined state is assigned to that window. In this work, the whole human epigenome was scanned with $1 \mathrm{~kb}$ non-overlaping windows. The epigenetic profile of a given window represents those epigenetic states across all samples, and can be seen as a vector of length 127 (epigenomic samples) where each component can take 15 possible values (epigenetic states). Finally, the "epigenetic correlation" between two genome windows ( $G i$ and $G j$ ) is quantified from their corresponding vectors as their "mutual information" (MI), an entropy-based parameter, according to the formula:

$$
\left.M I\left(G_{i}, G_{j}\right)\right)=\sum_{k=1}^{15} \sum_{l=1}^{15} P\left(G_{i k}, G_{j l}\right) \cdot \log _{2} \frac{P\left(G_{i k}, G_{j l}\right)}{P\left(G_{i k}\right) \cdot P\left(G_{j l}\right)}
$$

Where the sums run for the 15 possible epigenetic states. $P\left(G_{i k}\right)$ and $P\left(G_{j l}\right)$ are the frequencies of epigenetic states $\mathrm{k}$ and $\mathrm{l}$ in windows $G i$ and $G j$ respectively, and $P\left(G_{i k}, G_{j l}\right)$ the frequency of state $\mathrm{k}$ in window $G i$ matching state $\mathrm{l}$ in window $G j$ in the same samples. State undefined is ignored for this calculation, and the terms of the sums where either $P\left(G_{i k}\right)$ or $P\left(G_{j l}\right)$ are 0 are skipped. Consequently, this parameter has a high value for two windows when their epigenetic profiles correlate.

\section{Results}

Previous sequence similarity searches of Dido1 have proposed its role in chromatin stability, transcriptional regulation and cancer $(3,6)$. But additional experimental results accumulated over years, from our laboratory and others, support the proposed roles for Dido1 as well as raise new hypotheses $(4,5,7,8,20,56-58)$. It is also known that aberrant chromatin architecture causes transcriptional dysregulation, which is largely associated with cancer development and progression. Transcriptional dysregulation also plays a major role in other cancer hallmarks such as reprogramming of cell metabolism (63). In Figure 1 we summarize the DID03 annotations in different resources (Pfam domains, PROSITE motifs, and low-complexity regions).

The combined computational analysis of DIDO3 binding sites (ChIP-seq; GSE85029), transcriptome data of DID03AE16 (RNA-seq; GSE152346), and protein-protein interactions indicated that CT-domain is critical for the transcription of different subunits in large protein complexes. In Table 1 we defined a set of primary targets, with changes in expression upon DID03 deletion (DID03AE16) and DID03 binding over the whole gene, and secondary target with only expression changes without nearby DID03 ChIP-seq peak. For more details see Supplementary Table S1 and Supplementary Files 1 and 2. Importantly, some of the protein complexes highlighted in Table 1 regulate chromatin structure and function, including: CCCTC-binding factor (CTCF) through Bhlhe40, Cohesin, H3.3 chaperones, Polycomb repressor complex 2 (PRC2), SWI/SNF, and Set1/COMPASS. On the other hand, the unique and disordered CT-domain of DIDO3 (Figure 1) modulates RNA metabolism through enhancing its interactions with proteins $(8,58)$. In fact, interactions between DIDO3 and proteins whose encoding genes contain binding-sites in ChIP-seq (Table 2 and Supplementary Table S1) were confirmed by our group, using proximity ligation assay, co-purification, immunoprecipitation experiments, and proteomics analysis $(8,58)$. Such is the case of splicing factor SFPQ (58), helicase DHX9 that unwinds DNA and DNA:RNA hybrids (8), and chromatin decondensation factor NCL (58). 


\section{DIDO3 binding sites contribute to CTCF-mediated long-range chromatin interactions}

A re-analysis of ChIP-seq experiments in DIDO3 wild-type ESC (GSE85029) confirmed the co-localization of DID03 and RNAPII in the mouse genome. 79\% of DIDO3 sites (2269 out of 2888) overlap with RNAPII (Figure 2A and Supplementary Table S2). This result was expected to some extent based on previous work (4). But this analysis also revealed an unexpected overlap of DIDO3 binding sites with H3K36me3 (69\%, 2002 intersect sites), CTCF (13\%, 360 intersect sites), and PRC2 (8\%, 242 intersect sites) with significant p-values (Figure 2A and Supplementary Table S2). This result suggests a role of DIDO3 in chromatin organization as both, CTCF and PRC2 contribute to chromatin long-range interactions (60). Also, CTCF can attract other TFs to chromatin, including tissue-specific transcriptional activators, repressors, cohesin and RNAPII $(61,62)$.

We observed that various DID03 primary target genes (e.g., Dido1, Hmga1, Klf2, Smarcc1, Smarcad1, Pus3) listed in Table 1 and Supplementary Table S1, have been associated to intra-chromosomal CTCF-CTCF interactions in mESC (63). CTCF-loops can be affected by a downregulation of Bhlhe40 a DID03 secondary target gene detected in the RNA-seq of DIDO3 $\triangle$ E16 ESC (Table 1). BHLHE40 is a novel CTCF partner identified by co-immunoprecipitation experiments (64). It has been demonstrated that loss of BHLHE40 in HeLa-S3 cells led to reduction of CTCF binding to its recognition sites (i.e. a consensus sequence containing $\mathrm{CpG}$ dinucleotides), and to the disruption of CTCF-mediated long-range chromatin interactions (64). Altogether, considering the CTCF-TF cooperation in actively transcribed genes, and the downregulation of Bhlhe40, we suggest that DIDO3 may contribute to the regulation of CTCF-loops at specific loci.

\section{Regulation of cohesin complex formation}

Other genomic regions involved in higher-order chromatin organization (i.e. "insulator sites") have been associated to different functions, including: activation, repression, alternative splicing, and protection from DNA methylation. However, the molecular mechanisms behind these pleiotropic functions remain poorly understood (61). In this scenario of "insulator sites", we also identified a downregulation of Mau2 in the RNA-seq of DID03 $\triangle$ E16 ESC (Table 1). The chromatid cohesion factor MAU2 is a protein subunit of the cohesin-loading complex. Protein-coding gene Mau2 has a DIDO3 binding site in wild-type ESC and its downregulation in DID03 $\Delta$ E16 may affect CTCF-cohesin complex formation. We speculate that the downregulation of Mau2 could favour the CTCF self-association and clustering through internal RNA-binding regions in CTCF's Zinc fingers 1, 10, and 11 (65), thus affecting CTCF insulation function. Remarkably, RAD21 and SMC3 others subunit of the cohesincomplex also had a DID03 binding site in wild-type ESC (Table 2). Proteins MAU2, RAD21, and SMC3 interacted through the NIPBL-MAU2 heterodimer and the cohesin-complex composed of SMC1A, SMC3, RAD21 and STAG1. Taken together, these results point to the molecular interplay between DID03 and CTCF-cohesin complex.

Insulator sites showed a strong binding of the CTCF-cohesin complex, and are generally, but not always, flanked by distinct compartments on either side (61). Compartments refer to actively transcribed (open or A-compartment) and transcriptionally repressed (closed or B-compartment) regions. A recent study showed that the decrease of insulator-based long-range interactions causes deregulation of heterochromatic regions and formation of H3K27me3 "micro-domains" (2-8 nucleosomes) in distant euchromatin (66). Downregulation of Bhlhe40 and Mau2 in DID03 E16 ESC may contribute to the deregulation of heterochromatin and the spreading of H3K27me3 to distant gene loci (64). This could be an additional mechanism by which DID03 regulates gene expression in an epigenetic and structural context (see results below for TADs and compartments).

\section{DIDO3 may specifically bind to H3K36me3 through its PHD domain}

Intriguingly, DIDO3 seems to bind preferentially to two distinct sets of regions (Figure 2A and 2B). First to enhancers and promoters, overlapping with H4K27ac, H3K4me3 and CTCF. This result can be put in the context of DID03 binding to its own promoter, and regulating Dido1 transcriptional activation (5). Second DIDO3 binds to gene body and intergenic regions, overlapping with RNAPII and H3K36me3 respectively. In the intergenic regions, H3K36me3 is significantly isolated from any of the other mark we studied. This isolation of H3K36me3 means that it cannot be a secondary target of DID03 through any of the other studied mark, and that this interaction has thus a very high specificity. Overall the significant overlap between DIDO3 and H3K36me3 binding sites (69\%, 2002 intersect sites), and most importantly its high specificity in intergenic regions, prompted us to study the amino acid sequence of the PHD domain. The human DIDO3 PHD domain binds H3K4me3, and its crystallographic structure in complex with H3K4me3 is available (PDB ID: 4L7X) (4). Here, we compared the PHD amino acid sequences from mouse DIDO3 and yeast negative regulator of transcription elongation (BYE1), histone demethylase (ECM5), modulator of histone acetylation (NTO1), and histone ubiquitination (SNT2) proteins with selective binding of H3K4 or H3K36 tri-methylations (67) (Figure 2C). DID03 PHD domain showed the highest similarity (30\% sequence identity) with ECM5 and shares most of the key residues in the H3K36me3-binding pocket. According to the alignment and localization of residues in the crystallographic structure of DIDO3, we propose that Y267 in the equivalent position to ECM5-Y1240 could contribute to the H3K36me3 specificity. In this regard, the amino acid sequence flanking the K36 in mouse H3.3 is the most similar to yeast H3 (Figure 2C). All 
together, this observation puts DIDO3 in an unexpected place, as H3K36me3 in intergenic regions is related to facultative heterochromatin or DNA damage response $(68,69)$. This hypothesis about H3K36me3 binding is consistent with previous results that link DID03AE16 mutant to splicing defects (58). H3K36me3 is required for efficient pre-mRNA splicing (70).

\section{DIDO3 regulates nucleosome modifying and histone chaperone machinery complexes}

DIDO3 is a chromatin reader that recognizes H3K4me3 through its PHD domain (4), and also has a TF role in the Dido1 locus (5). As we said before for the CTCF-cohesin complex, we found DIDO3 binding sites in genes coding for different components of nucleosome modifying and histone chaperone machinery complexes, with few of them undergoing expression changes in DID03 $\triangle$ E16 ESC (Tables 1 and 2, and Supplementary Table S1).

The chromatin regulator SETD7, a primary target of DID03, illustrates the interconnected network of interactions. SETD7 interacts with Polycomb subunits EED and SUZ12 among other proteins. Of these chromatin and histone binding proteins, SETD7, EED, and SUZ12 had DID03 binding-sites in wild-type ESC (Tables 1 and 2), while the coding gene Setd7 was downregulated in DID03AE16 ESC (Table 1). Importantly, other coding genes for Polycomb accessory proteins (i.e. Aebp2, Epop) also had DIDO3 binding sites in wild-type ESC, and were transcriptionally upregulated in DID03 E16 ESC (Table 1).

Another result connecting our hypothesis with chromatin regulators was that SETD5 mediated trimethylation of H3K36 on active gene bodies (71). SETD5 interacts with the PAF1 complex, a general transcription elongation factor of the RNAPII. The ChIP-seq analysis revealed that H3K36me3 may be bound by DIDO3's PHD domain (69\% overlap, and seemingly exclusive overlap in intergenic regions, Figure 2A), which supported a functional relationship between SETD5 and DID03. Besides, Setd5 gene-loss in mice lead to abnormal transcription with impaired RNA maturation and detrimental effects on splicing, and Setd5 haploinsufficiency impaired the proliferation of neural progenitors and result in behavioural deficits in mice (71). RNA-seq of DID03 E16 ESC identified a downregulation of Setd5 (Table 1), and coincidentally, DID03 $\Delta$ E16 mutant produced splicing defects (58), and generated brain abnormalities and behavioural alterations in adult mice (57).

Various protein-coding genes linked to histone $\mathrm{H} 3$ modifications, chromatin remodelling, and transcriptional activation (e.g. H3f3a, H3f3b, Carm1, Kdm2a, Nsd1, and Mapk11) were identified in the ChIP-seq and transcriptome data of DID03. All these genes had DID03 binding-sites in wild-type ESC, while Carm1 and Mapk11 were also downregulated in DIDO3AE16 ESC (Tables 1 and 2). H3F3A and H3F3B represent an epigenetic imprint of transcriptionally active chromatin. CARM1 methylates histone $\mathrm{H} 3$ at Arg-17 leading to transcriptional activation through chromatin remodelling. NSD1 and KDM2A respectively write and erase the dimethylation of H3K36 (our proposed DID03 binding site). MAPK11 phosphorylates histone H3, and is a component of the MAP kinase (p38 MAPKs) signal transduction pathway. This pathway regulates chromatin modifiers and remodellers essentials for the initiation of chromatin condensation in mitosis and related to the activation of poised genes (72).

The last example comprised the link between DIDO3 and the regulation of heterochromatin. Based on the analysis of Hi-C (GSE99530), ChIP-seq (GSE85029), and RNA-seq (GSE152346) data in mice ESC we revealed that: i) about $12 \%$ (336 positions) of DID03 binding sites occurred in heterochromatic regions (Figure 2D), ii) the vast majority of DID03 binding sites co-localized in the 3D chromatin structure (Figure 2F), iii) $23-26 \%(11,467$ to 12,852 positions) of CTCF binding sites are located in heterochromatic regions (Figure 2D), iv) DIDO3 $\Delta$ E16 transcriptionally regulated the Polycomb accessory components Aebp2 and Epop, and v) insulator-based longrange interactions causing deregulation of heterochromatic regions could also be affected by DID03 $\Delta$ E16. In addition, the aggregate peak analysis (53) indicated that DIDO3 binding sites are close to RNAPII, H3K36me3, H3K4me3, and H3K27ac in the chromatin 3D structure of mESC (Figure 2F). The 3D spatial interaction of these proteins is more prominent in the DID03AE16 downregulated than in upregulated genes (Figure $2 \mathrm{~F}$, last two rows).

We detected DIDO3 binding sites in Cenpa, Cenph, Cenpv and Hjurp, reinforced by an observed upregulation of Cenpb and Cenpm in DID03 EE16 ESC (Table 1). These protein-coding genes are involved in the centromereassociated protein network and the histone H3 chaperone complex of CENP-A variant. We also observed a DIDO3 binding site in wild-type ESC and a downregulation of Trim28 in DID03 EE16 ESC (Table 1). TRIM28 is a scaffold protein of the heterochromatin protein 1 (CBX5/HP1A) present in the pericentric heterochromatin in the mouse centromere (73). Interestingly this observation can be linked to previous results based on that centromeric DNA is actively transcribed by RNAPII, and it is the presence of H3K4me1, H3K4me2, H3K36me2 and H3K36me3 that promotes RNAPII activity, and is essential for HJURP targeting and CENP-A assembly $(74,75)$.

\section{DIDO3 CT-domain affects gene expression of Polycomb components and different subunits of chromatin modifiers and remodeller complexes}

Polycomb mediates long-range chromatin interactions between distal genes, favouring transcriptional repression (60). Our meta-analysis of gene expression in DID03AE16 ESC (GSE152346), DID03 binding sites (GSE85029), and 
protein-protein interaction (PPI) data, revealed that DIDO3 could regulate long-distance chromatin contacts through the Polycomb-mediated interactions (Tables 1 and 2, and Figure 3).

Polycomb repressive complex II (PRC2) regulates pluripotency, differentiation, and tumorigenesis through catalysis of H3K27me3 on chromatin (68). The computational analysis presented here indicated that Eed, Ezh2, and Suz12 genes coding for the core subunits of PRC2 have DID03 binding sites in ESC, and that their encoded proteins are localized in densely connected regions of the PPI network (Table 2 and Figure 3 ). Other genes coding for accessory proteins of PRC2 such as Aebp2, Ctbp2, Elob (or Tceb2), Eloc (or Tceb1), Epop, Jarid2, and Pcl2 (or Mtf2) also had DIDO3 binding sites and some of their encoded proteins were localized as well in densely connected regions of the PPI network (Figure 3). But, more significantly, Aebp2 and Epop were overexpressed in DID03 $\Delta$ E16 ESC, suggesting that DIDO3 acts as a repressor for these genes (Table 1). AEBP2 is a DNA-binding transcriptional repressor specific for RNAPII. EPOP is a scaffold protein between the PRC2/EED-EZH2 complex and the elongin BC (ELOB-ELOC) complex, that plays a key role in genomic regions with both active and repressive chromatin properties - the so-called bivalent regions (76). These results agree with the hypothesis that alterations in the PRC2 recruitment in active chromatin contributes to the high number of overexpressed genes $524(66 \%)$ out of the 785 transcriptionally regulated in DID03 $\triangle \mathrm{E} 16$ ESC (Figure 3A). We also speculate that defective gene silencing lead to defective cell differentiation. In concordance with that, DIDO3 $\triangle \mathrm{E} 16$ impairs differentiation capacity in ESC, as has been experimentally determined (5).

Moreover, Phf1 and Mtf2 genes encode two H3K36me3 readers that recruits PRC2 to H3K36me3-containing chromatin regions (68). While Phf1 seems to be indirectly upregulated by DID03, as it is downregulated in DID03 $\Delta$ E16 ESC, the gene expression of Mtf2 was unaltered but presented a DIDO3 mark (Tables 1 and 2).

Other multiprotein complexes that maintain the precise gene expression states and prevent human pathologies are COMPASS and SWI/SNF. A misregulation of COMPASS, SWI/SNF, and PRC2 activities impairs the ratio of activated and repressed genes necessary for the maintenance of cell pluripotency and differentiation. Enhancer regions can be characterized by either high levels of H3K4me1 and H3K27me3 in poised enhancers or by H3K27ac in active enhancers. Indeed, in pluripotent cells it has been suggested that these bivalent regions are enriched at the developmental genes that are kept in a poised transcriptional state, ready to be activated or repressed upon stimulation by pro-differentiation signals. PRC2 mediates interactions between poised enhancers and developmental genes to facilitate their transcriptional induction upon differentiation (76). COMPASS can counteract H3K27me2/3 repressive marks deposited by PRC2, and thus favour H3K27ac. Here, we found that about $25 \%$ upregulated and 16\% downregulated genes in DID03 $\mathrm{E} 16$ (Figure 3C) were bona fide bivalent genes described in mouse ESC (76). In addition, bivalent genes are significantly upregulated compared to non-bivalent genes (Fisher's test: $\mathrm{p}=0.005$ ) according to RNA-seq data in DIDO3 $\Delta \mathrm{E} 16$.

The central core of COMPASS and COMPASS-related complexes is called WARD (or WRAD), because it is composed of WDR5, ASH2, RBBP5, and DPY30 proteins. Most of their coding genes Wdr5, Ash2l, and Dpy30 had DID03 binding sites in wild-type ESC (Table 2). In addition, WDR5 as well as PRC2 core proteins (EED, EZH2, SUZ12) were localized in densely connected regions of the PPI network (Figure 3B). Setd1b and Wdr82 genes that code for proteins of the Set1/COMPASS complex also have DID03 binding sites in ESC (Tables 1 and 2). SETD1B is a histone methyltransferase that specifically methylates Lys-4 of histone H3. Its coding gene, Setd1b, is overexpressed in DID03 3 E16 and thus repressed by DID03 in wild-type. It is thus reasonable to assume that this regulation may induce a decrease in H3K4me3 for which DID03 is a reader (Table 1). WDR82 is a regulatory component that facilitates histone H3 Lys4 methylation via recruitment of SETD1B to the Ser5 phosphorylated C-terminal domain of RNAPII large subunit. All these data suggested the contribution of DIDO3, and its connection to RNAPII, PRC2, and COMPASS in the regulation of gene expression dynamics during ESC self-renewal and differentiation.

The SWI/SNF (or BAF) complex is an ensemble of chromatin remodelling enzymes of around 15 subunits that hydrolyze ATP to mobilize nucleosomes and free DNA. This complex has a direct role in antagonizing Polycombmediated repression. Yet, SWI/SNF appears to also promote repression by Polycomb in stem cells and cancer $(77,78)$. Several genes encoding for SWI/SNF subunits, for example Arid1a, Bcl7b, Gltscr1l, Phf10, Smarca5, Smarcad1, Smarcc1, and Smarce1 have DID03 binding sites in wild-type ESC. Among them, Gltscr1l and Smarcad1 are upregulated, while Smarcc1 is downregulated in our RNA-seq data from DID03AE16 ESC (Tables 1 and 2). Specifically, the expression of Smarcc1 is necessary for heterochromatin formation and chromatin compaction during mouse ESC differentiation (77). Therefore, this finding suggests a deregulation in the mechanism of heterochromatin formation in DID03AE16 ESC. Downregulation of both Smarcc1 (SWI/SNF) and Phf1 (PRC2) exacerbated gene-silencing defects caused by DID03 $\triangle$ E16 in ESC. In the same line of evidences, a recent study reported that rapid SWI/SNF depletion leads to quick redistribution of PRC2 from highly occupied domains to weakly occupied sites genome-wide (78). This resulted in transcriptional derepression, chromatin decompaction, and opposite epigenomic changes to repressed domains (78). 
Our PPI-network analysis indicates that SMARCC1 is positioned in the same cluster that core proteins of PRC2 and COMPASS (Figure 3B). As mentioned before, SMARCC1 plays important roles in mouse ESC differentiation by coupling gene repression with global and local changes in chromatin structure (77). As well, protein interactions among SMARCC1 (SWI/SNF), WDR5 (COMPASS), and SUZ12 (PRC2) include the transcription factor POU5F1. Pou5f1 is a core stemness gene and a key regulator of self-renewal and differentiation in ESC. Previous experimental results from our laboratory demonstrated that gene expression of Pou5f1 and Dido1 are coordinated (8). Again, these results together supported the functional relationship we found among genes with DID03 binding sites in wild-type ESC, those with expression changes in DID03 E16 ESC, and regulation of the chromatin structure mediated by PRC2, COMPASS and SWI/SNF complexes.

\section{DIDO3 contributes to chromatin structure regulation}

As we said in the introduction, DID03AE16 ESCs did not differentiate in vitro, but maintained their self-renewal capacity $(7,8)$. Here, we also investigated the relationship between DID03 binding around transcription start sites (TSS) of up- and downregulated genes in DID03 E16 ESC (Figure 3D left pane). The frequency of DID03 binding sites around TSS $-50 \mathrm{~kb}$ upstream to $+50 \mathrm{~kb}$ downstream shows a similar distribution for upregulated and downregulated genes. We observe that the binding of DIDO3 in TSS is significantly higher than random in genes up- or down-regulated upon DID03 deletion of exon 16. However we observed that this increased specificity is comparable to other actors for which we had ChIP-seq (Figure 3D right panels). According to this, we hypothesize that DIDO3 is not the primary determinant, but it could be an accessory subunit for the RNAPII transcription activation and repression mechanisms.

Based on these results, we studied the relationships between DIDO3 binding sites, chromatin loops (e.g., CTCF and Polycomb), and TAD boundaries. The combined analysis of ChIP-seq (GSE85029, GSM2645517, GSM2645511, GSM2645495, GSM2645513, GSM2645515, GSM2645497, GSE120393, GSM2645509) and Hi-C data in mESC (GSE99530) shows enrichment for DIDO3, RNAPII, H3K36me3, H3K4me3, H3K27ac, and CTCF binding sites inside the chromatin loops (Figure 4A). Interestingly DID03 was found to be the mark most enriched in the inside of loops, between anchor points (positive coordinates in Figure 4A). In previous observations DID03 was overlapping to other marks, but here it can be differentiated from CTCF sites maintaining the loop and even, to a lesser extent, from RNAPII. We also defined six classes of chromatin loops (i.e., all, Polycomb, enhancer-promoter, CTCF, CTCF+enhancer-promoter, and CTCF-only) and analysed the enrichment of DID03, RNAPII, H3K36me3, H3K4me3, and H3K27ac within these classes in comparison with a random distribution (Figure 4B). This comparison indicated a significant enrichment for DIDO3 and RNAPII binding sites in the inside of "CTCF only" loops but not in "Polycomb" loops (Figure 4B). And following our observation about the presence of DID03 in the inside of chromatin loops, in Figure 4B we can narrow in this pattern to "CTCF only" loops suggesting that it can be a consequence of the physical occupancy of the CTCF and perhaps associated proteins. In the context of TAD boundaries (Figure 4C) we observed a significant enrichment CTCF protein but also of RNAPII and histone marks related to transcriptional activity (H3K4me3, H3K27ac, H3K36me3). Interestingly, among the proteins and histone marks measured, DIDO3 is, in proportion, the most enriched in TAD boundaries.

Finally, we also checked the distribution of DIDO3 marks in chromatin compartments. Overall, and as suggested by previous observations, DID03 marks were enriched in active A compartments (Figure 4D). We observed a similar distribution when looking at genomic bins (100 kb resolution) containing genes activated or repressed upon deletion of exon 16 of DID03 (DID03 $\mathrm{E} 16$ ) (Figure 4E). Up- and down-regulated genes seem to be respectively less and more in A compartments, but this small difference is hard to associate to the presence of DID03 marks as it may just be a consequence of their definition. For instance: down regulated genes show a tendency to be more $\mathrm{A}$ compartment, but probably because to be detected as "down-regulated" they need to show a decrease and thus start with a minimum level of activity.

\section{Similar epigenetic patterns suggest a co-regulatory role of DIDO3 and chromatin-associated complexes.}

Previously in this work, we identified some important chromatin regulation mechanisms altered by DID03 $\Delta$ E16 in mouse. Now we investigated these regulation mechanisms in human cells, and searched for correlated chromatin marks over the Dido1 locus and other regions genome-wide. For this, we applied the Epicorr v1.20 methodology (see Materials and Methods for details).

The Dido1 locus shows a variable epigenetic pattern across samples in a part of the locus $(\sim 61,545 \mathrm{~kb}-61,555 \mathrm{~kb}$ in chromosome 20) (Figure 5 top panel). Scanning all $1 \mathrm{~kb}$ windows within this fragment against all $1 \mathrm{~kb}$ windows of the 24 human chromosomes we identified 167 pairs of genomic regions with correlation score higher than 0.7 (a complete list of the regions is available at http://csbg.cnb.csic.es/pazos/DID01_epigen/). Among these correlated regions, we found enhancers, promoters, and coding regions associated to the human genes ARID1A, BCL11A, CENPA, CENPE, CENPF, HJURP, and CTBP2 (Figure 5 and Supplementary Table S3). Interestingly, the mouse homologous genes of ARID1A, CENPA, HJURP, and CTBP2 also had DIDO3 binding sites in wild-type ESC (Table 2). 
We know that Dido1 produces the same three protein isoforms by alternative splicing in mouse and human cells (2). In fact, mouse and human DIDO3 sequences are 75\% identical. All together, these results indicate that there is a co-regulatory role of DIDO3, HJURP/CENP-A chaperone complex, SWI/SNF, and PRC2 in both the mouse and human cells.

CENP-A is a centromere marker associated with chaperone HJURP in mammals, which facilitates deposition into chromatin $(79,80)$. Additionally, active RNAPII machinery is physically associated with CENP-A chromatin at early G1, as demonstrated in HeLa cells (81). Since DIDO3 binds to the RNAPII (5) and 78.6\% of its binding sites colocalize with the RPB1 subunit of RNAPII (Figure 2A and supplementary table S2), it is reasonable to think that DID03 CT-domain and RPB1 C-terminus domain cooperate in the assembly of a large macromolecular complex. DID03 CT-domain contains repetitive sequences and low-complexity regions that are commonly found in protein interfaces (Figure 1). Unfortunately, detailed structural data about the DID03 CT-domain in large protein complexes is not available yet.

To further analyse these 167 regions with an epigenetic pattern correlated to that in in Dido1 locus, we retrieved the genes matching these regions with bedtools (37). For that we downloaded from the NCBI the genome assembly our epigenomic data is based on (GRCh37.p13). Any gene overlapping, totally or partially, with the genome windows of interest was retrieved and a "functional enrichment analysis" was carried out with the topGO R package (https://bioconductor.org/packages/topGO/), using the Gene Ontology (50) annotations for the human genes downloaded from the NCBI. Among the list of significant terms we found two main categories: $i$ ) cell adhesion and signalling (in orange in supplementary file 3), and ii) cell division and chromosome segregation (in green in supplementary file 3). These two categories match the DID03 mutants phenotype in centromere localized DNA breaks (21) and in cellular differentiation defects $(5,8)$. These results in human and mouse strengthen the link between DIDO3 and centromere transcription, but also with the CTCF-cohesin complex in sister chromatid cohesion.

\section{Recurrent alterations in different cancer types accumulate in the DIDO3 splice-site and CT-domain}

It is known that deregulation of chromatin structure is associated with cancer development $(59,60)$. On the other hand, Dido1 gene alterations have been recently reported in small cohorts of cancer patients (Table 3). However, Dido1 is not classified as a potential cancer driver gene. We studied the distributions of Dido1 alterations, and the mutational pattern of other chromatin regulatory genes in a large cohort of patients. For this, we used the cBioPortal tool and the TCGA PanCancer dataset to study about 10,528 tumour samples with mutation, structural variants, and copy number alterations from 32 different studies. About 10,439 of the samples have mutations, and 9,896 have both mutations and copy number alterations.

The analysis revealed that only 415 (4\%) out of 10,439 queried samples have mutations in Dido1 (Figure 6A left panel). A total of 535 mutations (462 missense, 54 truncating, 16 splice-site, and 3 structural variants) were identified. The number of tumours with copy-number alterations in Dido1 was even lower: 211 (2\%) out of 9,896 queried samples, containing 208 amplifications and 3 deletions (Figure 6A right panel and Supplementary File 4). In addition, we investigated alterations in Dido1 gene expression in tumour samples. In general, the number of samples with gene expression data was lower in normal samples, and thus presents a higher variability (Supplementary Table S4). This high variability may be the reason why even-though 13 out of the 24 tumour types presented significant expression difference when compared to normal, these differences were over-expressions in tumour in only 9 of them. These result suggest either that Dido1 has a tumour specific mechanisms of action or, and being more conservative because of the high variability of the data, that Dido1 presents a similar average expression across the 24 tumour types (Figure 6B).

We also studied the distribution of mutations that were identified in at least two different samples along the DID03 amino acid sequence. Out of the 6 truncating mutations in Dido1, 4 are positioned in the DID03 CT-domain, after the PHD domain, and may thus be comparable to the DID03AE16 mutant (p.G1745Afs*119, p.P1908Lfs*111, p.P2034Rfs*240, and the splice site p.X1181_splice in Figure 6C).

Other genes coding for different components of the CTCF-cohesin, PRC2, SWI/SNF, Set1/COMPASS, and centromere-associated protein network showed gene expression changes upon DID03 $\Delta$ E16. Each of these macromolecular complexes coordinate their activities to regulate chromatin structure and gene expression dynamics $(60,73)$. Remarkably, according to the TCGA-PanCancer dataset, tumour samples with truncating mutations in the DID03 CT-domain (black dots, Figure 6C) also accumulate mutations in genes such as: BHLHE40 and MAU2 (CTCF-cohesin); AEBP2, EPOP, and PHF1 (PRC2); BICRAL, SMARCAD1, and SMARCC1 (SWI/SNF); SETD1B (Set1/COMPASS); CENPB and CENPM (centromere protein network), SETD5, SETD7, and TRIM28 (chromatin regulators). These genes are the human homologs of DID03 primary and secondary target genes in mouse ESC (Table 1). Except for CENPM, EPOP and SETD7, the remaining genes accumulated significantly more mutations in tumour samples with truncating mutations in the DID03 CT-domain (Fisher Exact test, P $<0.001$, 
according to cBioPortal)(Figure 6D). Taken together, these observations point again to the molecular interplay between DID03 and large macromolecular complexes that regulates chromatin structure and gene expression dynamics in mouse and human species.

\section{DISCUSSION}

Chromatin modifiers, TFs, CTCF-cohesin, and RNAPII are key regulators in gene expression mechanisms that ensure cellular differentiation (82-84). In the RNA-seq data, we observed an enrichment of genes coding for multiprotein complexes related to chromatin remodellers, chromatin binding, and histone modifiers among the upregulated and downregulated genes. Many of these multi-protein complexes interact with RNAPII and are at the crossroads of gene regulation and genome 3D architecture.

\section{A possible feedback loop between RNAPII transcription and DIDO3 targets}

RNAPII transcription is not only restricted to protein-coding and a large set of non-coding genes, but also widespread in intergenic regions (85). Accurate regulation of gene expression and repression mechanisms is essential for cell differentiation and cancer development processes. DIDO3 binds to the RNAPII (5) and DID03 3 E16 mutant shows altered RNA splicing and transcription termination in mESC and MEF $(8,58,86)$. Our analysis of ChIP-seq data indicates a significant overlap between the DID03, RNAPII, H3K36me3, H3K27ac, H3K4me3, and CTCF in mESC. Among the strongest colocalization signals is the colocalization between DIDO3 and H3K4me3, which is in agreement with experimental data about the specificity of the PHD domain (4). But we also found a significant overlap between DIDO3 and the repressive complex PRC2. However our analysis was not able to discern which of these interactions were due to direct interactions or to common targets. For instance the overlap between H3K4me3 and PRC2 is completely unexpected (87), and can only be explain because both may target promoter regions. In order to refine this analysis of colocalization, we divided the genome in sub-regions (promoter regions and intergenic regions). By this mean we were able to isolate some interesting signals. In intergenic regions, DID03 was no longer colocalizing with any mark or protein related to transcriptional repression suggesting that its colocalization with PRC2 at promoters may be, as it is also probably the case for H3K4me3, circumstantial. This analysis also revealed an interesting correlation: in intergenic regions DIDO3 and H3K36me3 colocalize significantly, while, at the same time, H3K36me3 is significantly separated from any other mark or protein tested. This result put H3K36me3 as a strong candidate to be a target of DIDO3. Following this hypothesis we compared DID03's PHD domain to other PHD domains with a H3K36me3 specific pocket and found a high sequence similarity. We believe that both of these observations suggest strongly that DIDO3 selectively recognizes and binds to $\mathrm{H} 3 \mathrm{~K} 36 \mathrm{me} 3$.

Based on our prediction that DIDO3 recognizes H3K36me3, we can reasonable describe its role in RNA splicing and transcription termination $(8,58,86)$. This claim is not simple to explain assuming that DID03's PHD domain binds to H3K4me3 (4). H3K36me3 has been associated with cryptic transcription, alternative pre-mRNA splicing, and 3D chromatin organization $(19,70)$. On the other hand, numerous studies have shown that CTCF mediates RNAPII pausing $(62,85,88)$ and RNA splicing events $(89,90)$, however the determinants of such distinct functions are still unknown. We hypothesize that the DIDO3 CT-domain not only alters interactions with splicing factor SFPQ (58) and helicase DHX9 (8), but also may contribute to the recruitment of other proteins crucial for the RNAPII processivity (e.g. HDAC1, CDK12, PAF1). Interestingly we also observed a possible feedback loop between protein subunits in large RNAPII-associated complexes and their coding genes, with a DIDO3 binding site. Our analysis of ChIP-seq data revealed that several of these actors coding genes were harbouring a DIDO3 binding site (RNAPII largest subunit RPB1 - Polr2a, splicing factor Sfpq, helicase Dhx9, H3K27ac specific histone deacetylase Hdac1, cyclin-dependent kinase $C d k 12$ which phosphorylates the C-terminal domain of RPB1 and regulates transcription elongation, RNAPII-associated factor Paf1 also involved in transcription elongation). Even if we were not able to find significant differences in gene expression in DID03 $\triangle \mathrm{E} 16$, we believe that they could be involved in this feedback loop. These findings raise new hypotheses that should be tested experimentally.

Different researchers have studied the interplay between RNAPII pausing and chromatin structure regulation (91). Here we postulate that DIDO3 contributes to RNAPII pausing and also to chromatin structure regulation.

\section{Role of DIDO3 in 3D chromatin structure}

The analysis of 3D colocalization performed through the aggregate peak analysis (APA) revealed similar patterns to that observed by overlapping ChIP-seq peaks in the linear genomic sequence. DID03 colocalizes mostly with indicators of transcriptional activity, as H3K4m3, H3K27ac, H3K36me3, RNAPII, active promoter and enhancers. To a lesser extent, but also significantly we found DIDO3 colocalizing with repressive Polycomb and H3K27me3. Finally, we found less interaction between DIDO3 and CTCF. This last observation contrasts with previous results showing a very clear overlap between CTCF bindings and DIDO3 bindings, suggesting that the interaction between DID03 and CTCF could be circumstantial (i.e. DID03 binds near promoters that happens to be close from CTCFCTCF loop anchors). This observation about the CTCF-DID03 link can also be related to the overlap of DID03 with 
CTCF-CTCF anchor points, the presence of CTCF at anchor points is negatively correlated with the presence of DID03, which seems to be displaced towards the inside of the loop (25 kb to $100 \mathrm{~kb}$ ). To be noted that this trend is not specific to DID03, we observed the same behaviour for RNAPII and histone marks related to active transcription, however this displacement is the strongest for DID03. With respect to DID03's location at TAD borders, we observed a clear enrichment, again following CTCF proteins and transcriptional activity. Finally, with respect to the location of genes marked with DID03 within A/B compartments, we observed an expected enrichment in A compartments. When dividing genes with DID03 marks into up- and down-regulated genes we observed that up-regulated genes in DID03 $\Delta$ E16 were more prone to be in B compartments while down-regulated genes, more in the active compartment type. As up-regulated genes must start at low expression level to detect increases in expression, and down-regulated must start expressed to detect repression, what we observed was surprising in the sense that even up-regulated genes (with currently low expression) were significantly far from Bcompartments. This observation that genes potentially directly down regulated by DIDO3 are in A-compartments is in favour of a very dynamic regulation.

\section{DIDO3 function as a transcription factor}

Although the exact mechanism underlying DID03 and DID03 $\Delta$ E16 mutant remains to be characterised, several possibilities can be proposed based on previous studies and our combined analysis of ChIP-seq, RNA-seq, and Hi-C data in $\mathrm{mESC}$ and MEF.

(1) RNAPII pausing. The RNAPII elongation rate can be controlled by chromatin 3D organisation and influence alternative splicing decisions. Interestingly, DID03 may participate in a transcription-coupled methylation/deacetylation mechanism allowing induced genes to be more rapidly repressed when their expression is no longer required. As we said before, the H3K36me2 specific methyltransferase Nsd1 and the H3K27ac specific deacetylase Hdac1 had a DIDO3 binding site, as well as primary or secondary targets histone methyltransferases specific Setd7 (H3K4me1), Setd1b (H3K4me2/3), Setd5 (H3K36me3). A second possible function of DIDO3 in a transcription-coupled methylation/deacetylation mechanism could be to reassemble a repressive chromatin configuration that switches off cryptic promoter-like sequences within transcribed regions, and repress antisense transcription in coding regions (92). This assumption is based on the predicted capacity of DIDO3 to bind H3K36me3 and its putative interaction with HDAC1. Both, H3K36me3 and histone deacetylase complexes provide a type of negative feedback to attenuate regulation of genes that must be not only activated but also repressed with the proper kinetics $(19,93)$. Once the DID03 PHD-domain recognizes H3K36me3, DID03 CTdomain (1080a.a. in mouse) in association with the C-terminal domain of RPB1 (377a.a. in mouse Supplementary FigureS1 in (94)) can recruit HDAC1 erasing acetylation on H3K27ac; thus preventing transcription initiation from cryptic promoter-like sequences within the body of genes. In addition, our ChIP-seq analysis indicates that the gene coding for PAF1, a putative DID03 interactor that modulates the RNAPII-elongation rates, also had a DID03 binding site in wild-type ESC. Other genes coding for proteins potentially involved in DIDO3 interactions, and required for pre-mRNA splicing and related to spliceosome assembly (Prpf4, Prpf6, Prpf38b, Prpf39, Srsf1, Srsf10, Srsf11) also had a DID03 binding site.

(2) Regulation of PRC2 guidance and DNA methylation. PRC2 is a protein complex that silences gene expression via epigenetic modifications of chromatin. But recently, single-molecular force spectroscopy experiments and computational simulations support the formation of a cooperative PRC2-mediated DNA loop (i.e. hairpin-like) and the implication of core subunits EZH2, SUZ12 and accessory AEBP2 (95). This study suggests that accessory proteins may regulate the genomic location of PRC2. Our combined analysis indicates that Ezh2, Suz12 and Aebp2 had DID03 binding sites, and moreover, Aebp2 is overexpressed in DID03AE16 mutant cells. Concerning DNA methylation, another transcriptional silencing mechanism, it has been suggested that DNA (cytosine-5)methyltransferases DNMT3A and DNMT3B bind to H3K36me3 epigenetic mark $(96,97)$. In addition, DNMT3B interacts with the PRC2/EED-EZH2 complex $(98,99)$. In the ChIP-seq data we detected DIDO3 binding sites on Dnmt3b, Kdm2a, and Hdac1. Histone demethylase KDM2A modify H3K36. Therefore, a cross talk between DIDO3 and H3K36me3 seems to potentially have a regulating role on DNA methylation through the complexes HDAC1DNMT3A-DNAMT3B, putting DID03 in the centre of the repressive marking of the chromatin.

(3) Regulation of SWI/SNF chromatin regulation complex. The ATP-dependent chromatin remodelling complexes (i.e. SWI/SNF) regulate the CTCF-cohesin-mediated chromatin interactions (100). SWI/SNF modulates the accessibility of naked DNA, can slide nucleosomes along DNA, and eject octamer histone core or histone dimers from chromatin. Then SWI/SNF facilitates the generation of nucleosome-free DNA, necessary for initiation of transcription, and in general binding of proteins such as CTCF. In this work we report the DIDO3 binding and transcription regulation by DID03 $\Delta \mathrm{E} 16$ of different components of SWI/SNF (Arid1a, Bcl7b, Smarcc1, Smarcad1, Smarca5/Snf2h, Smarce1, Gltscr1l/Bicral, Phf10).

(4) Misregulation of centromere associated proteins. In the ChIP-seq and RNA-seq data of mESC, Cenpa and Incenp had a DID03 binding site, while Birc5 is an overexpressed secondary target gene. Previous experiments with 
DID03 mutants found double-strand DNA breaks adjacent to centromeres, and related this finding to mitotic spindle defects (21). Other protein-coding genes involved in the centromere-associated protein network (i.e., Cenpb, Cenph, Cenpm, Cenpv, Hjurp, Mis18bp1, Dnmt3b) also had DID03 binding sites and/or were up-/downregulated in DIDO3 $\triangle \mathrm{E} 16$ mutant cells. In addition, our computational analysis in different human cells indicates a correlated pattern of chromatin marks over the DIDO1 locus and CENPA, CENPE, CENPF, and HJURP genomic regions.

(5) Regulation of Cohesin loading factors. Cohesin rings are needed to attach the sister chromatids before they are segregated. A misregulation of cohesin-loading or cohesin-release processes may cause mitotic defects due to precocious sister chromatid separation. Our combined analysis of ChIP-seq and RNA-seq data revealed that Mau2 and $\mathrm{Wapl}$, two cohesin-loading factors, had a DID03 binding site in wild-type mESC and Mau2 was downregulated in DID03 $\Delta \mathrm{E} 16$ mutant cells.

\section{CONCLUSION}

Overall, our findings indicate that DIDO3 is a keystone of RNAPII processivity that operates at the interface of transcription and chromatin structure regulation. We put together a selection of experimental results from our laboratory and others, and propose a new target for DIDO3 (H3K36me3). We also place DIDO3 in the spotlight of the chromatin structure regulation from the level of: $i$ ) promoter enhancer loops, ii) potential indirect interaction with CTCF, iii) regulation of cohesin loading complexes, iv) regulation of SWI/SNF, $v$ ) regulation of Polycomb specificity, vi) prevention/reparation of double strand breaks, and vii) regulation of proteins involved in chromosome segregation. In order to exactly understand the mechanisms allowing DID03 to regulate or at least intervene in these many aspects of RNAPII processivity and chromatin structure further experimental studies are needed. We believe that our work highlights the relevance of DID03 by proposing and confirming its implication in pathways essential to cellular differentiation, and related to cancer development.

\section{DATA AVAILABILITY}

The datasets supporting the conclusions of this article are accessible on the Gene Expression Omnibus (GE0) platform under accession number: GSE85029 (HA-DID03), GSM2645517 (Rpb1), GSM2645511 (H3K36me3), GSM2645495 (H3K4me3), GSM2645513 (H3K27ac), GSM2645497 (H3K27me3), GSM2645515 (CTCF), GSE120393 (PRC2), GSM2645509 (Ring1B) for ChIP-seq experiments; GSE152346 (DID03 and DID03 E16 in mouse embryonic stem cells) for RNA-seq experiments; and GSE99530 (mESC), GSE121087 and GSE115983 (MEF) for Hi-C experiments. RNA-seq data for DIDO3 and DID03 $\triangle E 16$ in mouse embryonic fibroblasts is accessible on the NCBI sequence read archive with accession number SRP150516 and PRJNA476070. The complete list of correlated genomic regions identified by Epicorr v1.20 is available at http://csbg.cnb.csic.es/pazos/DIDO_epigen/.

\section{ACKNOWLEDGMENTS}

The authors thank all members of the Stem cells and Immunity research group for early sharing of information and feedback on our manuscript.

\section{FUNDING}

This work was supported by grants SAF2016-75456-R and PID2019-110574RB-I00 (to C.M.A.) and PID2019108096RB-C22 (to F.P.) from the Spanish Ministerio de Ciencia e Innovacion, from the Comunidad de Madrid (MITIC) and from Intramural Project PIE $201920 \mathrm{E} 017$ (to C.M.A.). 


\section{REFERENCES}

1. García-Domingo D, Leonardo E, Grandien A, Martínez P, Albar JP, Izpisúa-Belmonte JC, et al. DIO-1 is a gene involved in onset of apoptosis in vitro, whose misexpression disrupts limb development. Proc Natl Acad Sci. 1999 Jul 6;96(14):7992-7.

2. Fütterer A, Campanero MR, Leonardo E, Criado LM, Flores JM, Hernández JM, et al. Dido gene expression alterations are implicated in the induction of hematological myeloid neoplasms. J Clin Invest. 2005 Sep 1;115(9):2351-62.

3. Rojas AM, Sanchez-Pulido L, Fütterer A, Wely KHM van, Martinez-A C, Valencia A. Death inducer obliterator protein 1 in the context of DNA regulation. FEBS J. 2005;272(14):3505-11.

4. Gatchalian J, Fütterer A, Rothbart SB, Tong Q, Rincon-Arano H, Sánchez de Diego A, et al. Dido3 PHD Modulates Cell Differentiation and Division. Cell Rep. 2013 Jul 11;4(1):148-58.

5. Fütterer A, Celis J de, Navajas R, Almonacid L, Gutiérrez J, Talavera-Gutiérrez A, et al. DIDO as a Switchboard that Regulates Self-Renewal and Differentiation in Embryonic Stem Cells. Stem Cell Rep. 2017 Apr 11;8(4):1062-75.

6. Sánchez-Pulido L, Rojas AM, van Wely KH, Martinez-A C, Valencia A. SPOC: A widely distributed domain associated with cancer, apoptosis and transcription. BMC Bioinformatics. 2004 Jul 7;5(1):91.

7. Fütterer A, Raya Á, Llorente M, Izpisúa-Belmonte JC, de la Pompa JL, Klatt P, et al. Ablation of Dido3 compromises lineage commitment of stem cells in vitro and during early embryonic development. Cell Death Differ. 2012 Jan;19(1):132-43.

8. Fütterer A, Talavera-Gutiérrez A, Pons T, de Celis J, Gutiérrez J, Domínguez Plaza V, et al. Impaired stem cell differentiation and somatic cell reprogramming in DIDO3 mutants with altered RNA processing and increased R-loop levels. Cell Death Dis. 2021 Jun 21;12(7):1-14.

9. Jang C-W, Shibata Y, Starmer J, Yee D, Magnuson T. Histone H3.3 maintains genome integrity during mammalian development. Genes Dev. 2015 Jul 1;29(13):1377-92.

10. Creyghton MP, Markoulaki S, Levine SS, Hanna J, Lodato MA, Sha K, et al. H2AZ Is Enriched at Polycomb Complex Target Genes in ES Cells and Is Necessary for Lineage Commitment. Cell. 2008 Nov 14;135(4):649-61.

11. Banaszynski LA, Wen D, Dewell S, Whitcomb SJ, Lin M, Diaz N, et al. Hira-Dependent Histone H3.3 Deposition Facilitates PRC2 Recruitment at Developmental Loci in ES Cells. Cell. 2013 Sep 26;155(1):107-20.

12. Hu G, Cui K, Northrup D, Liu C, Wang C, Tang Q, et al. H2A.Z Facilitates Access of Active and Repressive Complexes to Chromatin in Embryonic Stem Cell Self-Renewal and Differentiation. Cell Stem Cell. 2013 Feb 7;12(2):180-92.

13. Sarai N, Nimura K, Tamura T, Kanno T, Patel MC, Heightman TD, et al. WHSC1 links transcription elongation to HIRA-mediated histone H3.3 deposition. EMBO J. 2013 Aug 28;32(17):2392-406.

14. Soni S, Pchelintsev N, Adams PD, Bieker JJ. Transcription factor EKLF (KLF1) recruitment of the histone chaperone HIRA is essential for $\beta$-globin gene expression. Proc Natl Acad Sci. 2014 Sep 16;111(37):13337-42.

15. Zhang H, Gan H, Wang Z, Lee J-H, Zhou H, Ordog T, et al. RPA Interacts with HIRA and Regulates H3.3 Deposition at Gene Regulatory Elements in Mammalian Cells. Mol Cell. 2017 Jan 19;65(2):272-84. 
16. Piunti A, Shilatifard A. Epigenetic balance of gene expression by Polycomb and COMPASS families. Science [Internet]. 2016 Jun 3 [cited 2021 Apr 20];352(6290). Available from:

https://science.sciencemag.org/content/352/6290/aad9780

17. Martire S, Banaszynski LA. The roles of histone variants in fine-tuning chromatin organization and function. Nat Rev Mol Cell Biol. 2020 Sep;21(9):522-41.

18. Kasinath V, Beck C, Sauer P, Poepsel S, Kosmatka J, Faini M, et al. JARID2 and AEBP2 regulate PRC2 in the presence of H2AK119ub1 and other histone modifications. Science [Internet]. 2021 Jan 22 [cited 2021 Jun 26];371(6527). Available from:

https://science.sciencemag.org/content/371/6527/eabc3393

19. Fang Y, Tang Y, Zhang Y, Pan Y, Jia J, Sun Z, et al. The H3K36me2 methyltransferase NSD1 modulates H3K27ac at active enhancers to safeguard gene expression. Nucleic Acids Res. 2021 Jun 21;49(11):6281-95.

20. Trachana V, Wely KHM van, Guerrero AA, Fütterer A, Martínez-A C. Dido disruption leads to centrosome amplification and mitotic checkpoint defects compromising chromosome stability. Proc Natl Acad Sci. 2007 Feb 20;104(8):2691-6.

21. Guerrero AA, Gamero MC, Trachana V, Fütterer A, Pacios-Bras C, Díaz-Concha NP, et al. Centromerelocalized breaks indicate the generation of DNA damage by the mitotic spindle. Proc Natl Acad Sci. 2010 Mar 2;107(9):4159-64.

22. Braig S, Bosserhoff A-K. Death inducer-obliterator 1 ( Dido1) is a BMP target gene and promotes BMP-induced melanoma progression. Oncogene. 2013 Feb;32(7):837-48.

23. Egashira S, Jinnin M, Harada M, Masuguchi S, Fukushima S, Ihn H, et al. Exome sequence analysis of Kaposiform hemangioendothelioma: identification of putative driver mutations. An Bras Dermatol. 2016 Dec;91(6):748-53.

24. Berzoti-Coelho MG, Ferreira AF, de Souza Nunes N, Pinto MT, Júnior MCR, Simões BP, et al. The expression of Death Inducer-Obliterator (DIDO) variants in Myeloproliferative Neoplasms. Blood Cells Mol Dis. 2016 Jul 1;59:25-30.

25. Lyu P, Zhang S-D, Yuen H-F, McCrudden CM, Wen Q, Chan K-W, et al. Identification of TWISTinteracting genes in prostate cancer. Sci China Life Sci. 2017 Apr 1;60(4):386-96.

26. Siemers NO, Holloway JL, Chang H, Chasalow SD, Ross-MacDonald PB, Voliva CF, et al. Genome-wide association analysis identifies genetic correlates of immune infiltrates in solid tumors. PLOS ONE. 2017 Jul 27;12(7):e0179726.

27. Yang $\mathrm{P}$, Huang $\mathrm{X}$, Lai C, Li L, Li T, Huang $\mathrm{P}$, et al. SET domain containing $1 \mathrm{~B}$ gene is mutated in primary hepatic neuroendocrine tumors. Int J Cancer. 2019;145(11):2986-95.

28. Thutkawkorapin J, Lindblom A, Tham E. Exome sequencing in 51 early onset non-familial CRC cases. Mol Genet Genomic Med. 2019;7(5):e605.

29. Li J, Wang AS, Wang S, Wang CY, Xue S, Li WY, et al. Death-inducer obliterator 1 (DIDO1) silencing suppresses the growth of bladder cancer cells through decreasing SAPK/JNK signaling cascades. Neoplasma. 2020;67(05):1074-84.

30. Xiao J, Zhang R, Peng J, Yang Z. BAP1 maintains chromosome stability by stabilizing DID01 in renal cell carcinoma. Am J Cancer Res. 2020 May 1;10(5):1455-66. 
31. Assarnia S, Khales SA, Forghanifard MM. Correlation between SALL4 stemness marker and bone morphogenetic protein signaling genes in esophageal squamous cell carcinoma. J Biochem Mol Toxicol. 2019;33(3):e22262.

32. Forghanifard MM, Naeimi Khorasanizadeh P, Abbaszadegan MR, Javdani Mallak A, Moghbeli M. Role of DID01 in Progression of Esophageal Squamous Cell Carcinoma. J Gastrointest Cancer. 2020 Mar 1;51(1):83-7.

33. Zhang W, Mao J-H, Zhu W, Jain AK, Liu K, Brown JB, et al. Centromere and kinetochore gene misexpression predicts cancer patient survival and response to radiotherapy and chemotherapy. Nat Commun. 2016 Aug 31;7(1):12619.

34. Sharma AB, Dimitrov S, Hamiche A, Van Dyck E. Centromeric and ectopic assembly of CENP-A chromatin in health and cancer: old marks and new tracks. Nucleic Acids Res. 2019 Feb 20;47(3):1051-69.

35. Yu G, Wang L-G, He Q-Y. ChIPseeker: an R/Bioconductor package for ChIP peak annotation, comparison and visualization. Bioinformatics. 2015 Jul 15;31(14):2382-3.

36. Yu G, Wang L-G, Han Y, He Q-Y. clusterProfiler: an R Package for Comparing Biological Themes Among Gene Clusters. OMICS J Integr Biol. 2012 Mar 28;16(5):284-7.

37. Quinlan AR, Hall IM. BEDTools: a flexible suite of utilities for comparing genomic features. Bioinformatics. 2010 Mar 15;26(6):841-2.

38. Stovner EB, Sætrom P. PyRanges: efficient comparison of genomic intervals in Python. Bioinforma Oxf Engl. 2020 Feb 1;36(3):918-9.

39. Hagberg AA, Schult DA, Swart PJ. Exploring Network Structure, Dynamics, and Function using NetworkX. In: Varoquaux G, Vaught T, Millman J, editors. Proceedings of the 7th Python in Science Conference. Pasadena, CA USA; 2008. p. 11-5.

40. Serra F, Baù D, Goodstadt M, Castillo D, Filion GJ, Marti-Renom MA. Automatic analysis and 3Dmodelling of Hi-C data using TADbit reveals structural features of the fly chromatin colors. PLOS Comput Biol. 2017 Jul 19;13(7):e1005665.

41. Zhou Y, Zhou B, Pache L, Chang M, Khodabakhshi AH, Tanaseichuk O, et al. Metascape provides a biologist-oriented resource for the analysis of systems-level datasets. Nat Commun. $2019 \mathrm{Apr}$ 3;10(1):1523.

42. Pazos F, Garcia-Moreno A, Oliveros JC. Automatic detection of genomic regions with informative epigenetic patterns. BMC Genomics. 2018 Nov 28;19(1):847.

43. Cerami E, Gao J, Dogrusoz U, Gross BE, Sumer SO, Aksoy BA, et al. The cBio Cancer Genomics Portal: An Open Platform for Exploring Multidimensional Cancer Genomics Data. Cancer Discov. 2012 May 1;2(5):401-4.

44. Chandrashekar DS, Bashel B, Balasubramanya SAH, Creighton CJ, Ponce-Rodriguez I, Chakravarthi BVSK, et al. UALCAN: A Portal for Facilitating Tumor Subgroup Gene Expression and Survival Analyses. Neoplasia. 2017 Aug 1;19(8):649-58.

45. UniProt Consortium T. UniProt: the universal protein knowledgebase. Nucleic Acids Res. 2018 Mar 16;46(5):2699-2699.

46. Mistry J, Chuguransky S, Williams L, Qureshi M, Salazar GA, Sonnhammer ELL, et al. Pfam: The protein families database in 2021. Nucleic Acids Res. 2021 Jan 8;49(D1):D412-9. 
47. Hulo N, Bairoch A, Bulliard V, Cerutti L, De Castro E, Langendijk-Genevaux PS, et al. The PROSITE database. Nucleic Acids Res. 2006 Jan 1;34(suppl_1):D227-30.

48. Pertea M, Pertea GM, Antonescu CM, Chang T-C, Mendell JT, Salzberg SL. StringTie enables improved reconstruction of a transcriptome from RNA-seq reads. Nat Biotechnol. 2015 Mar;33(3):290-5.

49. Robinson MD, McCarthy DJ, Smyth GK. edgeR: a Bioconductor package for differential expression analysis of digital gene expression data. Bioinformatics. 2010 Jan 1;26(1):139-40.

50. Ashburner M, Ball CA, Blake JA, Botstein D, Butler H, Cherry JM, et al. Gene Ontology: tool for the unification of biology. Nat Genet. 2000 May;25(1):25-9.

51. Lieberman-Aiden E, Berkum NL van, Williams L, Imakaev M, Ragoczy T, Telling A, et al. Comprehensive Mapping of Long-Range Interactions Reveals Folding Principles of the Human Genome. Science. 2009 Oct 9;326(5950):289-93.

52. Roayaei Ardakany A, Gezer HT, Lonardi S, Ay F. Mustache: multi-scale detection of chromatin loops from Hi-C and Micro-C maps using scale-space representation. Genome Biol. 2020 Sep 30;21(1):256.

53. Rao SSP, Huntley MH, Durand NC, Stamenova EK, Bochkov ID, Robinson JT, et al. A 3D Map of the Human Genome at Kilobase Resolution Reveals Principles of Chromatin Looping. Cell. 2014 Dec 18;159(7):1665-80.

54. Kundaje A, Meuleman W, Ernst J, Bilenky M, Yen A, Heravi-Moussavi A, et al. Integrative analysis of 111 reference human epigenomes. Nature. 2015 Feb;518(7539):317-30.

55. Ernst J, Kellis M. Chromatin-state discovery and genome annotation with ChromHMM. Nat Protoc. 2017 Dec;12(12):2478-92.

56. Prieto I, Kouznetsova A, Fütterer A, Trachana V, Leonardo E, Alonso Guerrero A, et al. Synaptonemal complex assembly and H3K4Me3 demethylation determine DIDO3 localization in meiosis. Chromosoma. 2009 Oct 1;118(5):617-32.

57. Villares R, Gutiérrez J, Fütterer A, Trachana V, Burgo FG del, Martínez-A C. Dido mutations trigger perinatal death and generate brain abnormalities and behavioral alterations in surviving adult mice. Proc Natl Acad Sci. 2015 Apr 14;112(15):4803-8.

58. Mora Gallardo C, Sánchez de Diego A, Gutiérrez Hernández J, Talavera-Gutiérrez A, Fischer T, Martínez-A C, et al. Dido3-dependent SFPQ recruitment maintains efficiency in mammalian alternative splicing. Nucleic Acids Res. 2019 Jun 4;47(10):5381-94.

59. Feng Y, Pauklin S. Revisiting 3D chromatin architecture in cancer development and progression. Nucleic Acids Res. 2020 Nov 4;48(19):10632-47.

60. Jerković I, Szabo Q, Bantignies F, Cavalli G. Higher-Order Chromosomal Structures Mediate Genome Function. J Mol Biol. 2020 Feb 7;432(3):676-81.

61. Chandradoss KR, Chawla B, Dhuppar S, Nayak R, Ramachandran R, Kurukuti S, et al. CTCF-Mediated Genome Architecture Regulates the Dosage of Mitotically Stable Mono-allelic Expression of Autosomal Genes. Cell Rep [Internet]. 2020 Oct 27 [cited 2021 Apr 9];33(4). Available from: https://www.cell.com/cell-reports/abstract/S2211-1247(20)31291-2

62. Chernukhin I, Shamsuddin S, Kang SY, Bergström R, Kwon Y-W, Yu W, et al. CTCF Interacts with and Recruits the Largest Subunit of RNA Polymerase II to CTCF Target Sites Genome-Wide. Mol Cell Biol. 2007 Mar 1;27(5):1631-48. 
63. Handoko L, Xu H, Li G, Ngan CY, Chew E, Schnapp M, et al. CTCF-mediated functional chromatin interactome in pluripotent cells. Nat Genet. 2011 Jul;43(7):630-8.

64. Hu G, Dong X, Gong S, Song Y, Hutchins AP, Yao H. Systematic screening of CTCF binding partners identifies that BHLHE40 regulates CTCF genome-wide distribution and long-range chromatin interactions. Nucleic Acids Res. 2020 Sep 25;48(17):9606-20.

65. Hansen AS, Hsieh T-HS, Cattoglio C, Pustova I, Saldaña-Meyer R, Reinberg D, et al. Distinct Classes of Chromatin Loops Revealed by Deletion of an RNA-Binding Region in CTCF. Mol Cell. 2019 Nov 7;76(3):395-411.e13.

66. Heurteau A, Perrois C, Depierre D, Fosseprez O, Humbert J, Schaak S, et al. Insulator-based loops mediate the spreading of H3K27me3 over distant micro-domains repressing euchromatin genes. Genome Biol. 2020 Aug 3;21(1):193.

67. Shi X, Kachirskaia I, Walter KL, Kuo J-HA, Lake A, Davrazou F, et al. Proteome-wide Analysis in Saccharomyces cerevisiae Identifies Several PHD Fingers as Novel Direct and Selective Binding Modules of Histone H3 Methylated at Either Lysine 4 or Lysine 36 *. J Biol Chem. 2007 Jan $26 ; 282(4): 2450-5$.

68. Cai L, Rothbart SB, Lu R, Xu B, Chen W-Y, Tripathy A, et al. An H3K36 Methylation-Engaging Tudor Motif of Polycomb-like Proteins Mediates PRC2 Complex Targeting. Mol Cell. 2013 Feb 7;49(3):57182.

69. Li F, Mao G, Tong D, Huang J, Gu L, Yang W, et al. The Histone Mark H3K36me3 Regulates Human DNA Mismatch Repair through Its Interaction with MutS $\alpha$. Cell. 2013 Apr 25;153(3):590-600.

70. Leung CS, Douglass SM, Morselli M, Obusan MB, Pavlyukov MS, Pellegrini M, et al. H3K36 Methylation and the Chromodomain Protein Eaf3 Are Required for Proper Cotranscriptional Spliceosome Assembly. Cell Rep. 2019 Jun 25;27(13):3760-3769.e4.

71. Sessa A, Fagnocchi L, Mastrototaro G, Massimino L, Zaghi M, Indrigo M, et al. SETD5 Regulates Chromatin Methylation State and Preserves Global Transcriptional Fidelity during Brain Development and Neuronal Wiring. Neuron. 2019 Oct 23;104(2):271-289.e13.

72. Sawicka A, Seiser C. Histone H3 phosphorylation - A versatile chromatin modification for different occasions. Biochimie. 2012 Nov 1;94(11):2193-201.

73. Müller S, Almouzni G. Chromatin dynamics during the cell cycle at centromeres. Nat Rev Genet. 2017 Mar;18(3):192-208.

74. Arunkumar G, Melters DP. Centromeric Transcription: A Conserved Swiss-Army Knife. Genes. 2020 Aug;11(8):911.

75. Smurova K, De Wulf P. Centromere and Pericentromere Transcription: Roles and Regulation ... in Sickness and in Health. Front Genet [Internet]. 2018 [cited 2021 Jun 1];9. Available from: https://www.frontiersin.org/articles/10.3389/fgene.2018.00674/full

76. Mas G, Blanco E, Ballaré C, Sansó M, Spill YG, Hu D, et al. Promoter bivalency favors an open chromatin architecture in embryonic stem cells. Nat Genet. 2018 Oct;50(10):1452-62.

77. Schaniel C, Ang Y-S, Ratnakumar K, Cormier C, James T, Bernstein E, et al. Smarcc1/Baf155 Couples Self-Renewal Gene Repression with Changes in Chromatin Structure in Mouse Embryonic Stem Cells. STEM CELLS. 2009;27(12):2979-91. 
bioRxiv preprint doi: https://doi.org/10.1101/2021.09.27.462041; this version posted September 29, 2021. The copyright holder for this preprint (which was not certified by peer review) is the author/funder, who has granted bioRxiv a license to display the preprint in perpetuity. It is made available under aCC-BY-NC-ND 4.0 International license.

78. Weber CM, Hafner A, Braun SMG, Kirkland JG, Stanton BZ, Boettiger AN, et al. mSWI/SNF promotes polycomb repression both directly and through genome-wide redistribution. bioRxiv. 2020 Dec 7;2020.01.29.925586.

79. Foltz DR, Jansen LET, Bailey AO, Yates JR, Bassett EA, Wood S, et al. Centromere-Specific Assembly of CENP-A Nucleosomes Is Mediated by HJURP. Cell. 2009 May 1;137(3):472-84.

80. Dunleavy EM, Roche D, Tagami H, Lacoste N, Ray-Gallet D, Nakamura Y, et al. HJURP Is a Cell-CycleDependent Maintenance and Deposition Factor of CENP-A at Centromeres. Cell. 2009 May 1;137(3):485-97.

81. Quénet D, Dalal Y. A long non-coding RNA is required for targeting centromeric protein A to the human centromere. Manley JL, Shilatifard A, editors. eLife. 2014 Aug 12;3:e26016.

82. Panigrahi A, O'Malley BW. Mechanisms of enhancer action: the known and the unknown. Genome Biol. 2021 Apr 15;22(1):108.

83. Agrawal P, Rao S. Super-Enhancers and CTCF in Early Embryonic Cell Fate Decisions. Front Cell Dev Biol. 2021;9:653669.

84. Choi J, Lysakovskaia K, Stik G, Demel C, Söding J, Tian TV, et al. Evidence for additive and synergistic action of mammalian enhancers during cell fate determination. Ponting CP, Struhl K, Singh H, editors. eLife. 2021 Mar 26;10:e65381.

85. Gajos M, Jasnovidova O, van Bömmel A, Freier S, Vingron M, Mayer A. Conserved DNA sequence features underlie pervasive RNA polymerase pausing. Nucleic Acids Res [Internet]. 2021 Mar 31 [cited 2021 Apr 13];(gkab208). Available from: https://doi.org/10.1093/nar/gkab208

86. Mora Gallardo C, Sánchez de Diego A, Martínez-A C, van Wely KHM. Interplay between splicing and transcriptional pausing exerts genome-wide control over alternative polyadenylation. Transcription. 2021 Aug 7;0(0):1-17.

87. Schmitges FW, Prusty AB, Faty M, Stützer A, Lingaraju GM, Aiwazian J, et al. Histone Methylation by PRC2 Is Inhibited by Active Chromatin Marks. Mol Cell. 2011 May 6;42(3):330-41.

88. Luan J, Xiang G, Gómez-García PA, Tome JM, Zhang Z, Vermunt MW, et al. Distinct properties and functions of CTCF revealed by a rapidly inducible degron system. Cell Rep [Internet]. 2021 Feb 23 [cited 2021 Apr 16];34(8). Available from: https://www.cell.com/cell-reports/abstract/S22111247(21)00096-6

89. Shukla S, Kavak E, Gregory M, Imashimizu M, Shutinoski B, Kashlev M, et al. CTCF-promoted RNA polymerase II pausing links DNA methylation to splicing. Nature. 2011 Nov;479(7371):74-9.

90. Alharbi AB, Schmitz U, Marshall AD, Vanichkina D, Nagarajah R, Vellozzi M, et al. Ctcf haploinsufficiency mediates intron retention in a tissue-specific manner. RNA Biol. 2021 Jan 2;18(1):93-103.

91. Francette AM, Tripplehorn SA, Arndt KM. The Paf1 Complex: A Keystone of Nuclear Regulation Operating at the Interface of Transcription and Chromatin. J Mol Biol. 2021 Apr 1;166979.

92. Chantalat S, Depaux A, Héry P, Barral S, Thuret J-Y, Dimitrov S, et al. Histone H3 trimethylation at lysine 36 is associated with constitutive and facultative heterochromatin. Genome Res. 2011 Sep 1;21(9):1426-37.

93. Keogh M-C, Kurdistani SK, Morris SA, Ahn SH, Podolny V, Collins SR, et al. Cotranscriptional Set2 Methylation of Histone H3 Lysine 36 Recruits a Repressive Rpd3 Complex. Cell. 2005 Nov 18;123(4):593-605. 
bioRxiv preprint doi: https://doi.org/10.1101/2021.09.27.462041; this version posted September 29, 2021. The copyright holder for this preprint (which was not certified by peer review) is the author/funder, who has granted bioRxiv a license to display the preprint in perpetuity. It is made available under aCC-BY-NC-ND 4.0 International license.

94. Pons T, Paramonov I, Boullosa C, Ibáñez K, Rojas AM, Valencia A. A common structural scaffold in CTD phosphatases that supports distinct catalytic mechanisms. Proteins Struct Funct Bioinforma. 2014;82(1):103-18.

95. Lin X, Leicher R, Liu S, Zhang B. Cooperative DNA looping by PRC2 complexes. Nucleic Acids Res [Internet]. 2021 May 31 [cited 2021 Jun 12];(gkab441). Available from: https://doi.org/10.1093/nar/gkab441

96. Rondelet G, Dal Maso T, Willems L, Wouters J. Structural basis for recognition of histone H3K36me3 nucleosome by human de novo DNA methyltransferases 3A and 3B. J Struct Biol. 2016 Jun 1;194(3):357-67.

97. Rinaldi L, Datta D, Serrat J, Morey L, Solanas G, Avgustinova A, et al. Dnmt3a and Dnmt3b Associate with Enhancers to Regulate Human Epidermal Stem Cell Homeostasis. Cell Stem Cell. 2016 Oct 6;19(4):491-501.

98. Viré E, Brenner C, Deplus R, Blanchon L, Fraga M, Didelot C, et al. The Polycomb group protein EZH2 directly controls DNA methylation. Nature. 2006 Feb;439(7078):871-4.

99. Kim S-H, Park J, Choi M-C, Park J-H, Kim H-P, Lee J-H, et al. DNA methyltransferase 3B acts as a corepressor of the human polycomb protein hPc2 to repress fibroblast growth factor receptor 3 transcription. Int J Biochem Cell Biol. 2008 Jan 1;40(11):2462-71.

100. Alpsoy A, Sood S, Dykhuizen EC. At the Crossroad of Gene Regulation and Genome Organization: Potential Roles for ATP-Dependent Chromatin Remodelers in the Regulation of CTCF-Mediated 3D Architecture. Biology. 2021 Apr;10(4):272. 


\section{Table and Figure Legends}

\section{Table 1. Primary and secondary target genes with expression changes between DID03AE16 and WT ESC}

(a) Gene position is represented by chromosome (Chr) number and strand directions in parenthesis (forward (+) and reverse $(-)$ ); (b) Unique MACS2 identifiers of ChIP-seq peak according to the HA-DID03 dataset (GSE85029); (c) Gene expression changes, $\log 2$ fold change $\left(\log _{2} \mathrm{FC}\right)$ and adjusted p-values (FDR) between DID03 $\mathrm{E} 16$ and WT ESC, were calculated from RNAseq data in edgeR. (d) UniProtKB annotations (www.uniprot.org). Hyphens (-) indicate that ChIP-seq peaks were not detected.

\section{Table 2. Genes with DIDO3 binding-sites and their proteins would have DIDO3 interactions}

(a) Gene position is represented by chromosome (Chr) number and strand directions in parenthesis (forward (+) and reverse $(-))$; (b) Unique MACS2 identifiers of ChIP-seq peak according to the HA-DID03 dataset (GSE85029); (c) UniProtKB annotations (www.uniprot.org).

\section{Table 3. Cancer types with Dido1 genetic alterations reported in the literature}

(a) The two alleles present at each Dido1 locus contain the genetic variant. Hyphens (-) indicate that heterozygosity is not provided.

\section{Figure 1. Scheme of protein isoforms produced by alternative splicing of the Dido1 gene}

Amino acids start and end positions for the Pfam domains, PROSITE motifs, and low-complexity regions are indicated in parenthesis using the numbering scheme of the mouse sequence (UniProtKB accession number: Q8C9B9). Experimentally determined protein interactions are also shown at bottom. PHD: PHD finger; TFIIS_M: Transcription factor S-II central domain; SPOC: Spen paralogue and orthologue C-terminal domain; NLS_BP: Bipartite nuclear localization signal; ZF_PHD_1 and ZF_PHD_2: Zinc finger PHD-type; TFIIS_CENTRAL: TFIIS central domain; CCT: CCT domain; ARG_RICH: Arginine-rich region; PRO_RICH: Proline-rich region; THR_RICH: Threonine-rich region; GLU_RICH: Glutamic acid-rich region; ASP_RICH: Aspartic acid-rich region. Rojas et al (3) predicted a dPHD domain of approximately 25 amino acids -not shown here- and positioned 67 residues downstream of the PHD domain. The annotations about protein domains, motifs, and low-complexity regions are publicly available at: http://pfam.xfam.org/ and https://prosite.expasy.org (last accessed on May 12, 2021).

\section{Figure 2. DID03 binding sites intersection with RNAPII, CTCF, Polycomb, and histone H3 modifications}

(A) Distribution of intersects peaks (i.e., DIDO3, RNAPII, CTCF, Polycomb, and H3 modifications over chromosomes. (B) Percentage of intersects peaks across promoters and intergenic regions. (C) Sequence comparison among PHD domains and histone $\mathrm{H} 3$ variants in yeast and mouse. We also show the PHD 3D-structure and the position of key residues in the peptidebinding pocket. (D) Percentage of DIDO3 and CTCF peaks in euchromatin and heterochromatin regions. (E) Example of APA in polar coordinates showing the average interaction enrichment between DIDO3 and H3K36me3 coordinates (F) Colocalization of DID03 binding sites with other ChIP-seq marks in the 3D chromatin structure of mouse ESC. First row show DID03 marks against other marks with not filters. Second row shows the interaction between marks near any gene. Third row shows the interaction between marks near gene upregulated in DID03 $\Delta$ E16. Fourth row shows the interaction between marks near gene downregulated in DID03 EE16. Proximity between gene and mark requires any overlap inside the same $5 \mathrm{~kb}$ bin.

Figure 3. DID03 target genes coding for Polycomb subunits and chromatin modifiers are interconnected. (A) Circlos plot of the genes detected in ChIP-seq and RNA-seq data. (B) Protein-protein interactions network and densely connected sub-networks detected by MCODE. (C) Percentage of bivalent genes up- and down-regulated in DID03 $\triangle E 16$ ESC. (D) Frequency of DID03 binding sites around TSS ( $-50 \mathrm{~kb}$ upstream to $50 \mathrm{~kb}$ downstream) of the up- and down-regulated genes compare to a random distribution.

\section{Figure 4. DID03 is tightly linked to chromatin structure.}

Active promoter category are promoter regions with both H3K27ac and H3K4me3 marks, enhancers regions enriched in H3K27ac at least $40 \mathrm{~kb}$ away from any gene position of ChIP-seq marks with respect to loop anchor points. Positive coordinates represent the inside of loops (between loop anchor points). (A) Overall position of ChIP-seq marks around loop anchor points. Notches in boxplots represent $95 \%$ confidence of the median after 1.000 bootstraps. (B) Enrichment of ChIP-seq marks around loop anchor points with 100 bootstraps error band. In grey are shown the result of 100 randomizations of the ChIP-seq mark coordinates. all are any loop detected by the software Mustache. Enhancer-promoter loops are loops with anchor points away from PRC2 or Ring1B (> $20 \mathrm{~kb}$ ) and close to H3K27ac or H3K4me3 $(<40 \mathrm{~kb})$. CTCF loops are loops with anchor points away from PRC2 or Ring1B ( $>20 \mathrm{~kb})$ and close to CTCF marks $(<20 \mathrm{~kb})$. CTCF + enh-prom loops are loops with anchor points away from PRC2 or Ring1B ( $>20 \mathrm{~kb}$ ), close to H3K27ac or H3K4me3 (<40 kb) and close to CTCF marks (<20 kb). CTCF only loops are loops with anchor points away from PRC2 or Ring1B or H3K27ac or H3K4me3 (> $20 \mathrm{~kb}$ ), and close to CTCF marks (<20 kb). (C) Same as (A) with TAD borders detected by TADbit. (D) Distribution of compartment scores in all $100 \mathrm{~kb}$ genomic bins (left), bins containing up regulated genes in DID03 $\Delta \mathrm{E} 16$, down regulated genes in DID03 $\triangle \mathrm{E} 16$, bins with DID03 ChIP-seq mark, bins with the mark and upregulated genes, and finally (right) bins with the mark and down regulated genes. (E) Changes in A/B compartment score in mESC and mEF highlighting in black bins with DIDO3 mark in mESC, in red bins with the mark and genes with significant expression increase in mESC, and, in blue bins with the mark and genes with significant expression decrease in mESC. 


\section{Figure 5. Genomic regions with informative epigenetic patterns}

The epigenetic state of each 200 bp portion (small boxes) is indicated with colors. For details, see legend at the top left panel. The two discussed Dido1 regions (1000 bp windows) are highlighted in large boxes, surrounded by their epigenomic neighborhood. The names of the epigenetic sample groups are on the top right corner, colored using the tissue-based color schema of the Roadmap Epigenomics Consortium.

Figure 6. Dido1 genetic alterations in the TCGA-PanCancer dataset. (A) Bar plot of the Dido1 missense mutations, copy-number alterations, and predictions of gene fusions. (B) Box plot of Dido1 mRNA expression in normal and tumour samples according to the UALCAN web-portal (http://ualcan.path.uab.edu). Significantly different TPM values (Student's t-test, $\mathrm{P}<0.001$ ) in normal-vs-tumour samples were indicated with an asterisk $\left({ }^{*}\right.$ ). (C) Lolliplots showing the distribution of coding variants (i.e., missense, nonsense and frameshift variants) across DID03 functional domains. (D) Mutation frequency of DID03 primary and secondary targets in tumor samples with "truncating mutations" in the DID03 CT-domain. $\left(^{*}\right)$ Indicates statistical significance (Fisher Exact test, P < 0.001). 
bioRxiv preprint doi: https://doi.org/10.1101/2021.09.27.462041; this version posted September 29, 2021. The copyright holder for this preprint (which was not certified by peer review) is the author/funder, who has granted bioRxiv a license to display the preprint in perpetuity. It is made available under aCC-BY-NC-ND 4.0 International license.

Table 1

\begin{tabular}{|c|c|c|c|c|}
\hline Gene & $\boldsymbol{C h r}$ (a) & ChIP-seq (b) & RNA-seq (c) & Description (d) \\
\hline \multicolumn{5}{|c|}{ Primary target gene } \\
\hline Setd7 & Chr3 (-) & \#1718 & $\begin{array}{l}\log _{2} \mathrm{FC}=-0.86 \\
\mathrm{FDR}=1.16 \mathrm{e}-02\end{array}$ & Histone methyltransferase (H3K4me1) \\
\hline Carm1 & Chr9 (+) & \#2735 & $\begin{array}{l}\log _{2} \mathrm{FC}=-0.81 \\
\mathrm{FDR}=1.73 \mathrm{e}-03\end{array}$ & Histone methyltransferase (H3R17me2) \\
\hline Dido1 & Chr2 (-) & $\# 1664$ to \#1671 & $\begin{array}{l}\log _{2} \mathrm{FC}=-4.81 \\
\mathrm{FDR}=1.21 \mathrm{e}-11\end{array}$ & H3K4me3 reader, RNA pol II associated \\
\hline Hmga1 & Chr17 (+) & $\# 1174, \# 1175$ & $\begin{array}{l}\log _{2} \mathrm{FC}=-1.56 \\
\mathrm{FDR}=2.77 \mathrm{e}-10\end{array}$ & Nucleosome phasing \\
\hline Mau2 & Chr8 (-) & \#2626, \#2627 & $\begin{array}{l}\log _{2} \mathrm{FC}=-3.03 \\
\mathrm{FDR}=3.24 \mathrm{e}-16\end{array}$ & Cohesin-loading complex (chromatid cohesion factor) \\
\hline Trim28 & Chr7 (+) & \#2336 & $\begin{array}{l}\log _{2} \mathrm{FC}=-0.81 \\
\mathrm{FDR}=1.73 \mathrm{e}-03\end{array}$ & $\begin{array}{l}\text { Scaffold protein for the heterochromatin protein } 1 \\
\text { (CBX5/HP1A) }\end{array}$ \\
\hline Aebp2 & Chr6 (+) & \#2299, \#2300 & $\begin{array}{l}\log _{2} \mathrm{FC}=2.12 \\
\mathrm{FDR}=8.72 \mathrm{e}-08\end{array}$ & Polycomb accessory protein (PRC2) \\
\hline Eрор & Chr11 (-) & \#509, \#508 & $\begin{array}{l}\log _{2} \mathrm{FC}=1.00 \\
\mathrm{FDR}=1.44 \mathrm{e}-08\end{array}$ & Polycomb accessory protein (PRC2) \\
\hline Set1b/Setd $1 b$ & Chr5 (+) & \#2148 & $\begin{array}{l}\log _{2} \mathrm{FC}=1.01 \\
\mathrm{FDR}=2.7 \mathrm{e}-03\end{array}$ & $\begin{array}{l}\text { Set1/COMPASS complex protein, methyltransferase } \\
\text { activity }(\mathrm{H} 3 \mathrm{~K} 4 \mathrm{me} 2 / 3)\end{array}$ \\
\hline Smarcc1 & $\operatorname{Chr} 9(+)$ & \#2838 & $\begin{array}{l}\log _{2} \mathrm{FC}=-1.25 \\
\mathrm{FDR}=1.51 \mathrm{e}-04\end{array}$ & SWI/SNF complex, chromatin remodeling \\
\hline Smarcad1 & Chr6 (+) & \#2225 & $\begin{array}{l}\log _{2} \mathrm{FC}=0.92 \\
\mathrm{FDR}=2.02 \mathrm{e}-02\end{array}$ & SWI/SNF complex, chromatin remodeling \\
\hline Gltscr1l/Bicral & Chr17 (-) & \#1242 & $\begin{array}{l}\log _{2} \mathrm{FC}=0.88 \\
\mathrm{FDR}=3.35 \mathrm{e}-04\end{array}$ & SWI/SNF complex, chromatin remodeling \\
\hline \multicolumn{5}{|c|}{ Secondary target gene (downstream) } \\
\hline Bhlhe40 & Chr6 (+) & - & $\begin{array}{l}\log _{2} \mathrm{FC}=-1.44 \\
\mathrm{FDR}=3.46 \mathrm{e}-07\end{array}$ & Novel CTCF binding partner \\
\hline Birc5/Survivin & Chr11 (+) & - & $\begin{array}{l}\log _{2} \mathrm{FC}=7.76 \\
\mathrm{FDR}=3.35 \mathrm{e}-03\end{array}$ & $\begin{array}{l}\text { Recruitment of chromosome passage protein complex } \\
\text { (CPC) to centromeres }\end{array}$ \\
\hline Cenpb & Chr2 (-) & - & $\begin{array}{l}\log _{2} \mathrm{FC}=0.81 \\
\mathrm{FDR}=2.19 \mathrm{e}-03\end{array}$ & Centromere-associated protein \\
\hline Cenpm & Chr15 (-) & - & $\begin{array}{l}\log _{2} \mathrm{FC}=0.73 \\
\mathrm{FDR}=1.21 \mathrm{e}-02\end{array}$ & Centromere-associated protein \\
\hline Mapk11 & Chr15 (-) & - & $\begin{array}{l}\log _{2} \mathrm{FC}=-0.95 \\
\mathrm{FDR}=1.82 \mathrm{e}-02\end{array}$ & $\begin{array}{l}\text { Phosphorylate histone } \mathrm{H} 3 \text { and the Nucleosomal protein } \\
\text { HMGN1 }\end{array}$ \\
\hline Pcl1/Phf1 & Chr17 (+) & - & $\begin{array}{l}\log _{2} \mathrm{FC}=-1.71 \\
\mathrm{FDR}=4.2 \mathrm{e}-02\end{array}$ & Polycomb accessory protein (PRC2), H3K36me3 reader \\
\hline Setd5 & Chr6 (+) & - & $\begin{array}{l}\log _{2} \mathrm{FC}=-4.17 \\
\mathrm{FDR}=3.28 \mathrm{e}-26\end{array}$ & Histone methyltransferase (H3K36me3) \\
\hline
\end{tabular}


bioRxiv preprint doi: https://doi.org/10.1101/2021.09.27.462041; this version posted September 29, 2021. The copyright holder for this preprint (which was not certified by peer review) is the author/funder, who has granted bioRxiv a license to display the preprint in perpetuity. It is made available under aCC-BY-NC-ND 4.0 International license.

Table 2

\begin{tabular}{|c|c|c|c|}
\hline Gene & Chr (a) & ChIP-seq ${ }^{(b)}$ & Description (c) \\
\hline Set & Chr2 (+) & \#1490,\#1491 & Nucleosome assembly and histone chaperone \\
\hline Ep300 & Chr15 (+) & \#969 & Histone acetyltransferase (H3K122ac, H3K27ac) \\
\hline Hdac1 & Chr4 (-) & $\# 1915$ & Histone deacetylase (H3K27ac) \\
\hline Hsp90aa1 & Chr12 (-) & \#678, \#679, \#680 & $\begin{array}{l}\text { Modulate histone deacetylases and participate in the } \\
\text { eviction of histones from the promoter region }\end{array}$ \\
\hline$H 3 f 3 a$ & Chr1 (-) & \#143 & Histone H3.3 \\
\hline$H 3 f 3 b$ & Chr11 (-) & \#556, \#557, \#558 & Histone H3.3 \\
\hline Hjurp & Chr1 (-) & \#82 & H3 chaperone complex of CENP-A variant \\
\hline Cenpa & Chr5 (+) & $\# 2062$ & Centromere-associated protein, CENP-A variant \\
\hline Cenph & Chr13 (-) & $\# 808, \# 809, \# 810$ & Centromere-associated protein \\
\hline Cenpv & Chr11 (-) & $\# 403$ & Centromere-associated protein \\
\hline Mis18bp1 & Chr12 (-) & $\# 635$ & Required for recruitment of CENP-A to centromeres \\
\hline Dnmt3b & $\operatorname{Chr} 2(+)$ & \#1592 & $\begin{array}{l}\text { DNA methyltransferase } 3 \mathrm{~B}(\mathrm{CpG} \text { in pericentromeric). } \\
\text { Interacts with centromere-associated protein CENP-C }\end{array}$ \\
\hline Cdca8 & Chr4 (-) & $\# 1900$ & Chromosomal passenger complex (CPC) protein \\
\hline Incenp & Chr19 (-) & $\# 1402, \# 1403$ & Chromosomal passenger complex (CPC) protein \\
\hline$K d m 2 a$ & Chr19 (-) & $\begin{array}{l}\# 1362, \# 1363, \\
\# 1364\end{array}$ & Histone demethylase (H3K36me2) \\
\hline Nsd1 & Chr13 (+) & $\# 747, \# 748$ & Histone methyltransferase (H3K36me2) \\
\hline $\operatorname{Morf} 412 / \operatorname{Mrg} x$ & $\operatorname{ChrX}(-)$ & \#2885 & Binds H3K36me2/3, yeast Eaf3 homolog \\
\hline Psip1 & Chr4 (-) & \#1858, \#1859, \#1860 & Binds H3K36me3, recruits splicing factors \\
\hline $\mathrm{Ncl}$ & Chr1 (-) & \#76, \#77, \#78, \#79 & $\begin{array}{l}\text { Induces chromatin decondensation by binding to } \\
\text { histone } \mathrm{H} 1\end{array}$ \\
\hline Snw1 & Chr12 (-) & $\# 670$ & Spliceosome component, yeast Prp45 homolog \\
\hline Prpf4 & Chr4 (+) & $\# 1856$ & Pre-mRNA splicing, U4/U6-U5 tri-snRNP complex \\
\hline Prpf6 & Chr2 (+) & \#1682 & Pre-mRNA splicing, U4/U6-U5 tri-snRNP complex \\
\hline Prpf38b & Chr3 (-) & \#1782 & Pre-mRNA splicing \\
\hline Prpf39 & Chr12(+) & \#631, \#632, \#633 & Pre-mRNA splicing \\
\hline $\operatorname{Rad} 21$ & Chr15 (-) & $\# 935$ & Cohesin complex \\
\hline Smc3 & Chr19 (+) & \#1441 & Cohesin complex \\
\hline Wapl & Chr14 (+) & \#836 & Regulates cohesin loading onto chromatin \\
\hline Eed & Chr7 (-) & $\# 2469, \# 2470$ & Polycomb core protein (PRC2) \\
\hline Ezh2 & Chr6 (-) & $\# 2215$ & Polycomb core protein (PRC2) \\
\hline Suz12 & Chr11 (+) & $\# 464$ & Polycomb core protein (PRC2) \\
\hline Ctbp2 & Chr7 (-) & \#2559 & Polycomb accessory protein (PRC2) \\
\hline Elob/Tceb2 & $\operatorname{Chr} 17(-)$ & $\# 1150$ & Polycomb accessory protein (PRC2) \\
\hline Eloc/Tceb1 & Chr1 (-) & $\# 22$ & Polycomb accessory protein (PRC2) \\
\hline Jarid2 & Chr13 (+) & $\# 736, \# 737$ & Polycomb accessory protein (PRC2) \\
\hline Pcl2/Mtf2 & Chr5 (+) & $\# 2115$ to $\# 2118$ & Polycomb accessory protein (PRC2) \\
\hline$W d r 5$ & Chr2 (+) & \#1476, \#1477 & COMPASS complex, core protein (WARD) \\
\hline Ash2l & Chr8 (-) & $\# 2603, \# 2604$ & COMPASS complex, core protein (WARD) \\
\hline Dpy30 & Chr17 (-) & \#1272,\#1273 & COMPASS complex, core protein (WARD) \\
\hline Wdr82 & Chr9 (+) & \#2827, \#2828, \#2829 & Set1/COMPASS complex protein \\
\hline Arid1a & Chr4 (-) & \#1933, \#1934 & SWI/SNF complex, chromatin remodeling \\
\hline$B c l 7 b$ & Chr5 (+) & \#2169 & SWI/SNF complex, chromatin remodeling \\
\hline Smarca5/Snf2h & Chr4 (+) & \#1962, \#1963 & SWI/SNF complex, chromatin remodeling \\
\hline Smarce1 & Chr11 (-) & $\# 525$ & SWI/SNF complex, chromatin remodeling \\
\hline Phf10 & $\operatorname{Chr17}(-)$ & \#1117 & SWI/SNF complex, chromatin remodeling \\
\hline
\end{tabular}


bioRxiv preprint doi: https://doi.org/10.1101/2021.09.27.462041; this version posted September 29, 2021. The copyright holder for this preprint (which was not certified by peer review) is the author/funder, who has granted bioRxiv a license to display the preprint in perpetuity. It is made available under aCC-BY-NC-ND 4.0 International license.

Table 3

\begin{tabular}{lcccc}
\hline Cancer type & Cohort size & Genetic alteration & Heterozygosity (a) & Reference \\
\hline Melanoma & $\mathrm{n}=8$ & Dido1 expression & - & 25 \\
\hline $\begin{array}{l}\text { Kaposiform } \\
\text { Hemangioendothelioma }\end{array}$ & $\mathrm{n}=1$ & p.E49* & Homo & 26 \\
\hline Chronic Myeloid Leukemia & $\mathrm{n}=60$ & Dido1 expression & - & 27 \\
\hline Prostate & $\mathrm{n}=281$ & Dido1 expression & - & 28 \\
\hline Head and neck & $\mathrm{n}=279$ & $\begin{array}{l}\text { loss-of-function } \\
\text { mutations, CNVs }\end{array}$ & - & 29 \\
\hline Hepatic neuroendocrine & $\mathrm{n}=22$ & p.D850H, p.I749M & - & 30 \\
\hline Colorectal & $\mathrm{n}=51$ & p.R1145H & - & 31 \\
\hline Bladder & $\mathrm{n}=20$ & Dido1 expression & - & 32 \\
\hline Kidney clear cell renal cell & $\mathrm{n}=34$ & Dido1 expression & - & 33 \\
\hline Esophageal squamous cell & $\mathrm{n}=50$ & Dido1 expression & - & 34 \\
\hline
\end{tabular}


bioRxiv preprint doi: https://doi.org/10.1101/2021.09.27.462041; this version posted September 29, 2021 . The copyright holder for this preprint (which was not certified by peer review) is the author/funder, who has granted bioRxiv a license to display the preprint in perpetuity. It is made available under aCC-BY-NC-ND 4.0 International license.

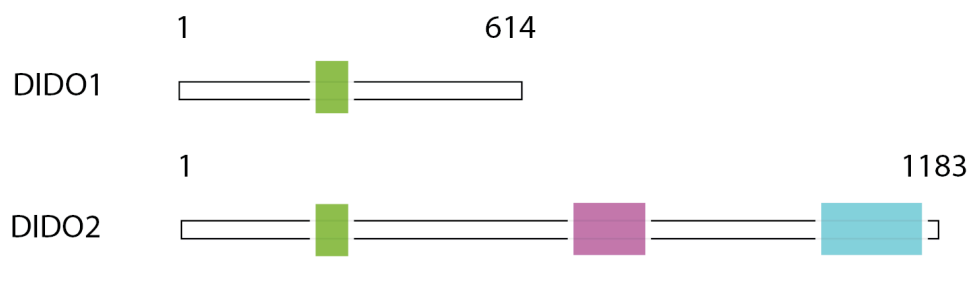

1

$\mathrm{DIDO3}$

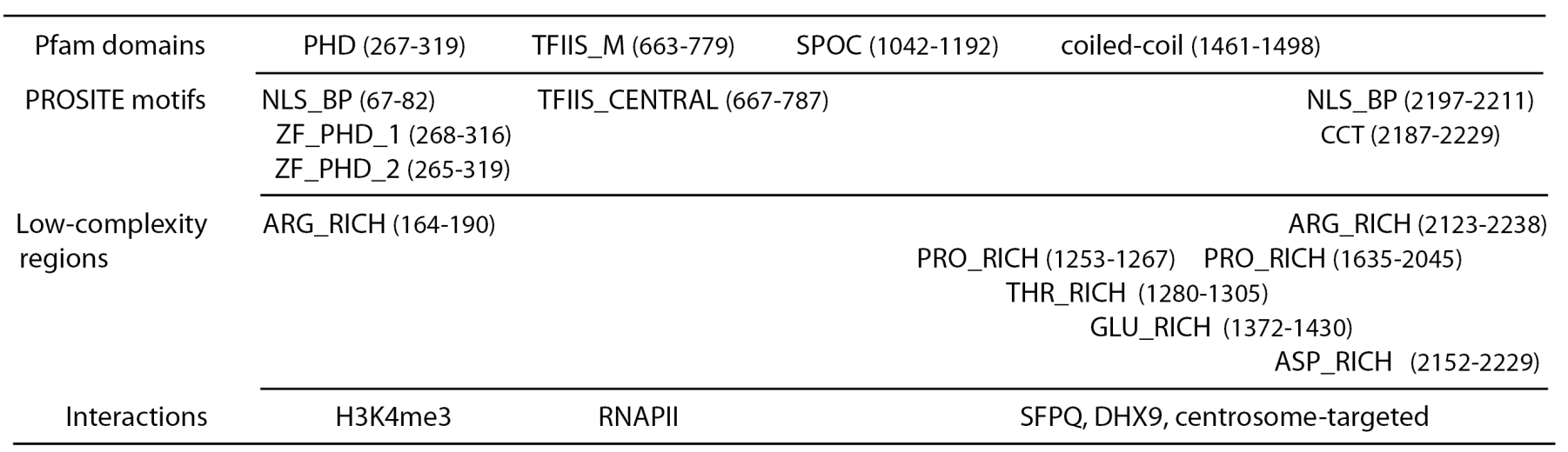

\section{Figure 1}


bioRxiv preprint doi: https://doi.org/10.1101/2021.09.27.462041; this version posted September 29, 2021. The copyright holder for this preprint (which was not certified by peer review) is the author/funder, who has granted bioRxiv a license to display the preprint in perpetuity. It is made available under aCC-BY-NC-ND 4.0 International license.

A
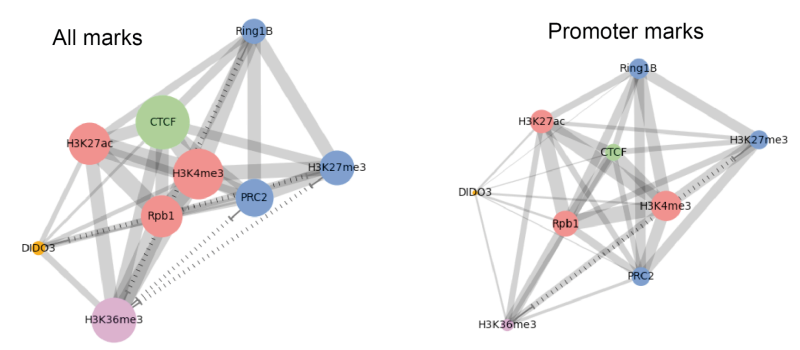

Intergenic marks

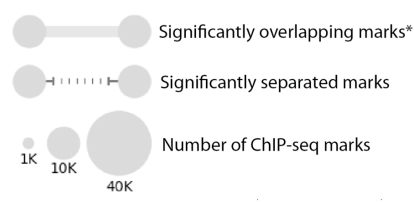

*width proportional to intersection

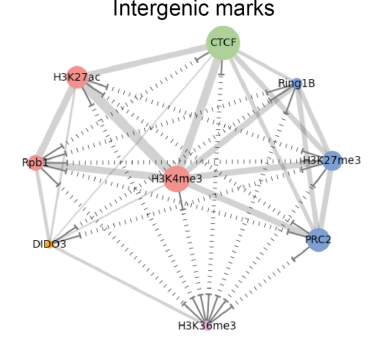

B

\begin{tabular}{ccc} 
Feature & Promoter & Intergenic \\
\hline HA-DIDO3 3 & $8.7 \%$ & $30.4 \%$ \\
\hline \multicolumn{3}{c}{ DIDO3 overlapping sites } \\
\hline RPB1 & $10.6 \%$ & $23.1 \%$ \\
H3K36me3 & $8.8 \%$ & $20.0 \%$ \\
H3K27ac & $18.1 \%$ & $19.7 \%$ \\
H3K4me3 & $27.1 \%$ & $13.8 \%$ \\
CTCF & $15.0 \%$ & $23.6 \%$ \\
ED:EZH2:SUZ12 & $19.4 \%$ & $10.7 \%$ \\
RING1B & $43.9 \%$ & $4.9 \%$ \\
H3K27me3 & $22.7 \%$ & $0.0 \%$ \\
\hline
\end{tabular}

D

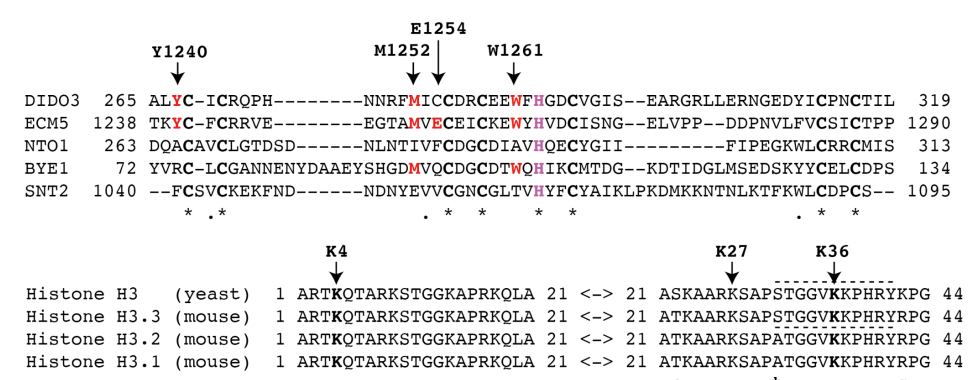

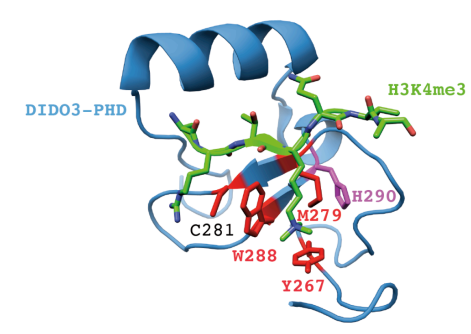

euchromatin
(A-compartment) $\quad \begin{aligned} & \text { heterochromatin } \\ & \text { (B-compartment) }\end{aligned}$

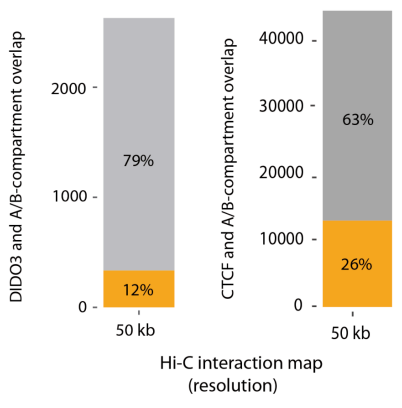

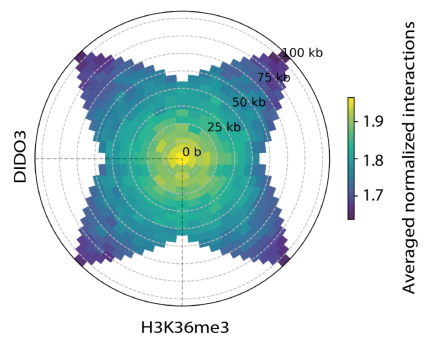

$\mathbf{F}$

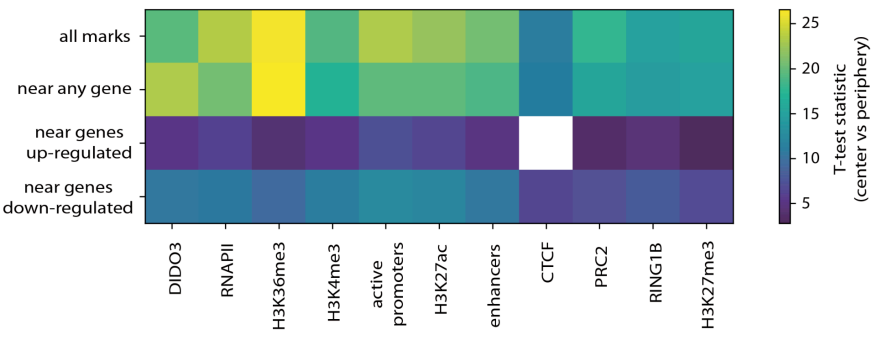

Figure 2 
bioRxiv preprint doi: https://doi.org/10.1101/2021.09.27.462041; this version posted September 29, 2021. The copyright holder for this preprint (which was not certified by peer review) is the author/funder, who has granted bioRxiv a license to display the preprint in perpetuity. It is made available under aCC-BY-NC-ND 4.0 International license.

A

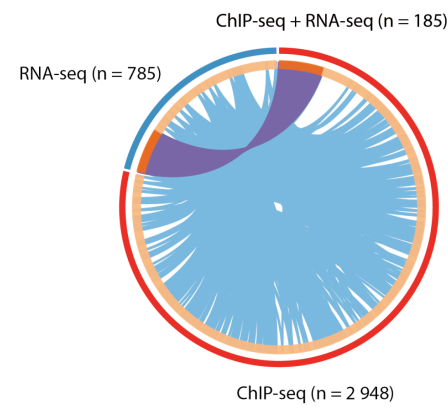

C

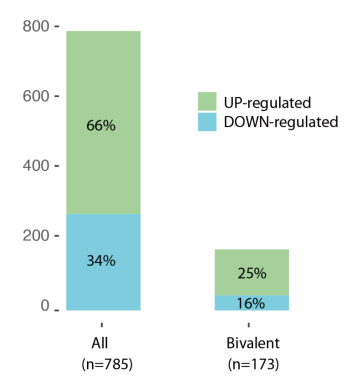

D

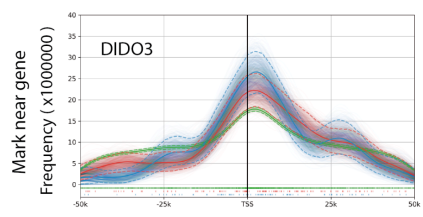

B
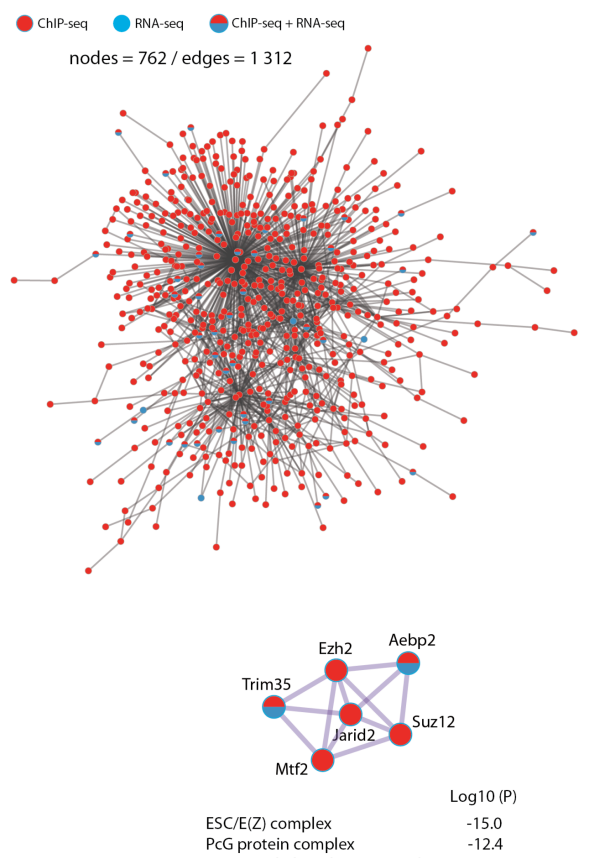

PRC2 methylates histones and DNA -12.4
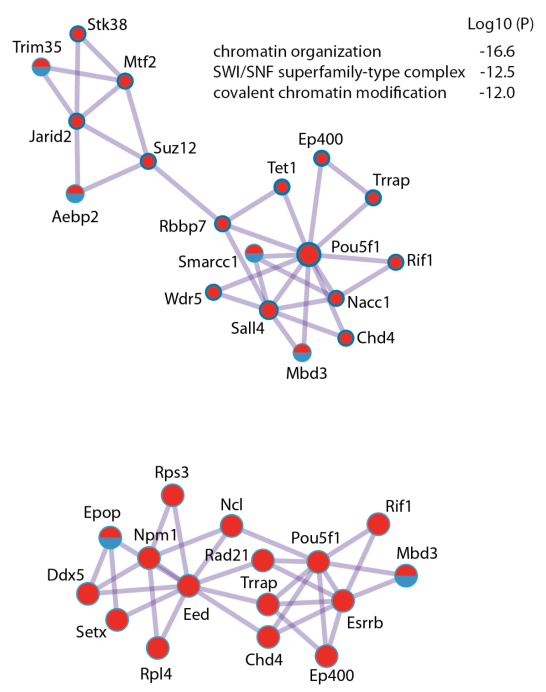

$\log 10(P)$

chromatin binding

-9.7
-9.3
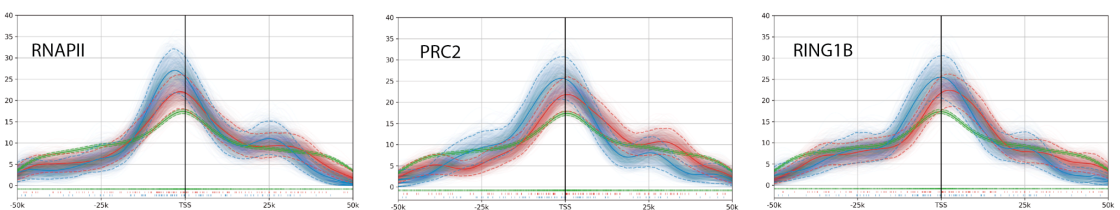

Mark position with respect to TSS

— any gene ( +1000 transparent bootstraps) - - any gene $95 \%$ conf. — up regulated ( +1000 transparent bootstraps) -- up regulated $95 \%$ conf. — down regulated ( +1000 transparent bootstraps) -- down regulated $95 \%$ conf.

\section{Figure 3}


bioRxiv preprint doi: https://doi.org/10.1101/2021.09.27.462041; this version posted September 29, 2021. The copyright holder for this preprint (which was not certified by peer review) is the author/funder, who has granted bioRxiv a license to display the preprint in perpetuity. It is made available under aCC-BY-NC-ND 4.0 International license.

A

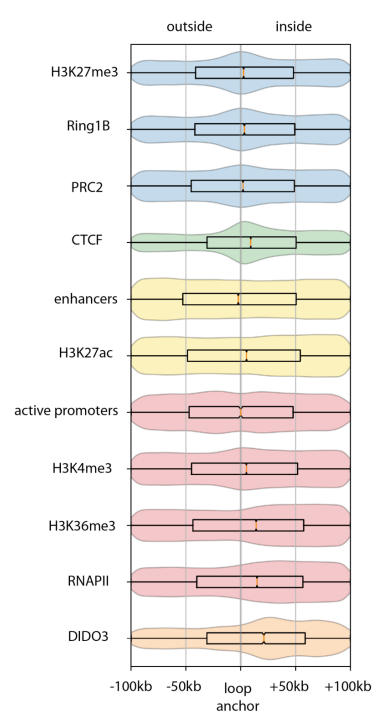

c

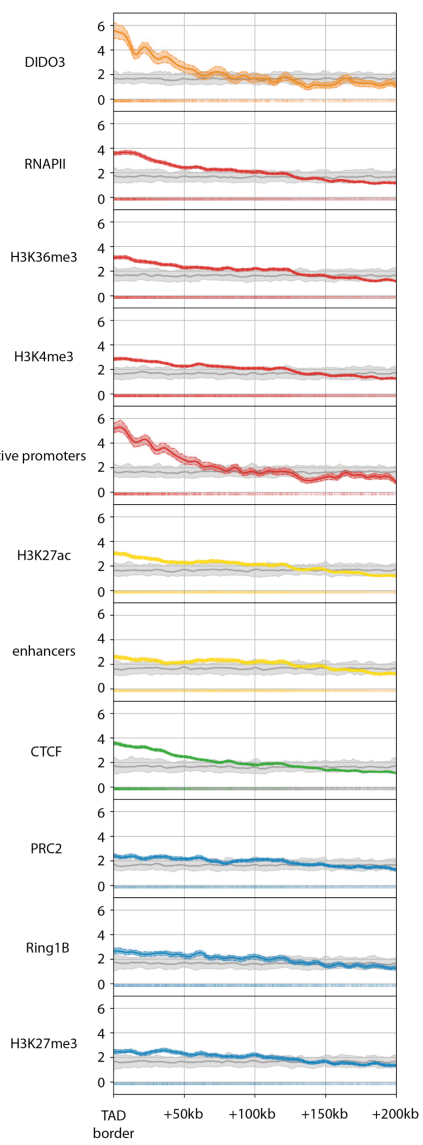

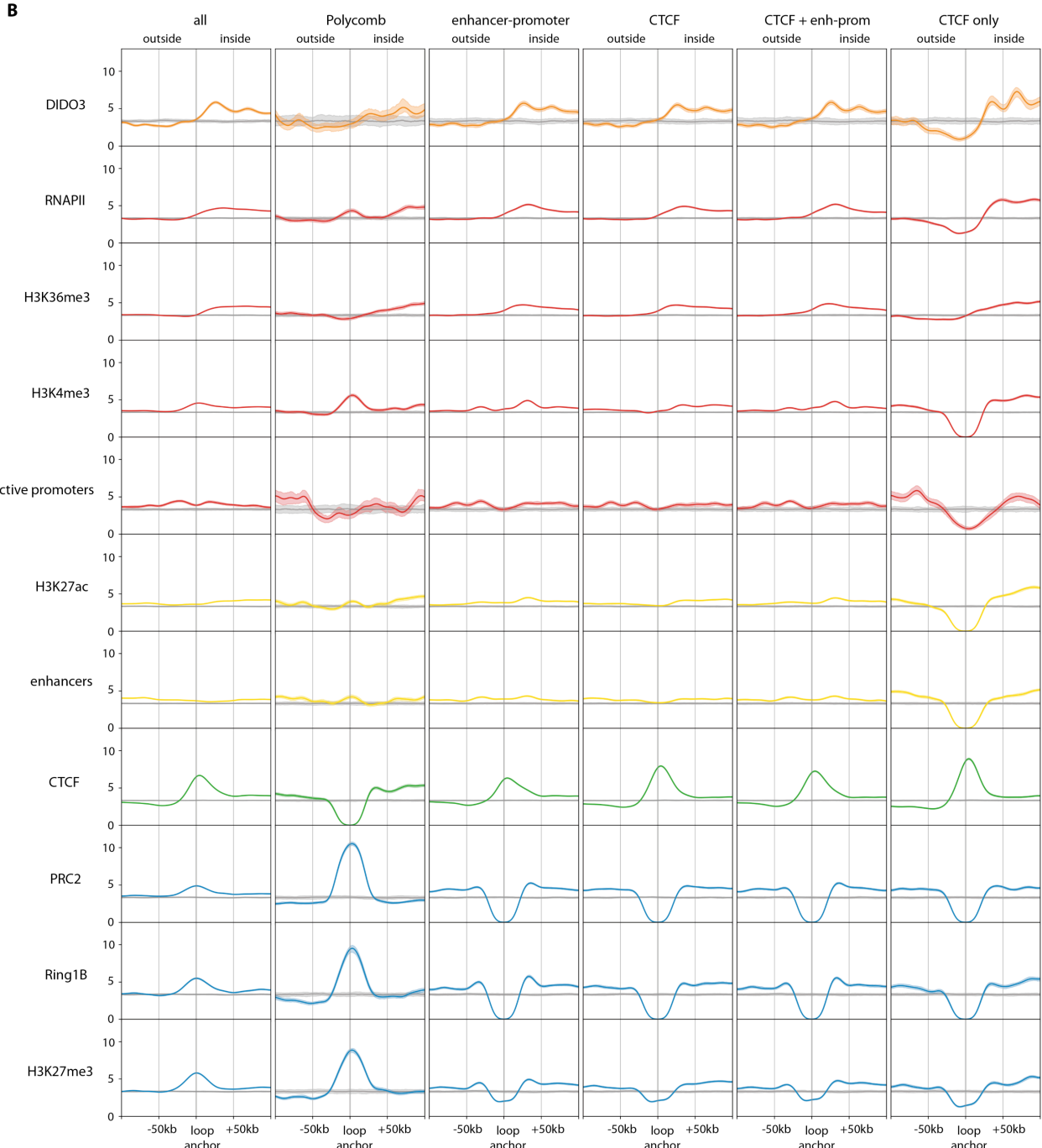

D

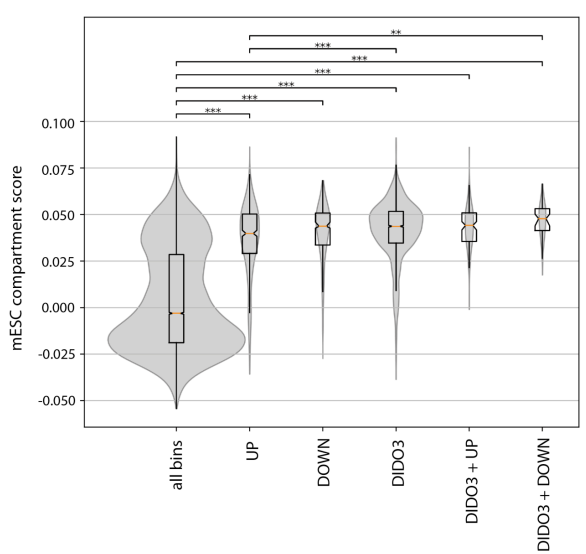

E

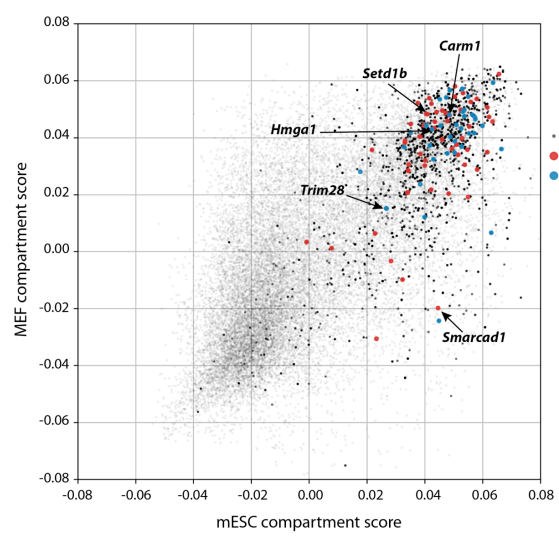

DIDO3

\section{Figure 4}


bioRxiv preprint doi: https://doi.org/10.1101/2021.09.27.462041; this version posted September 29, 2021. The copyright holder for this

preprint (which was not certified by peer review) is the author/funder, who has granted bioRxiv a license to display the preprint in perpetuity. It is made available under aCC-BY-NC-ND 4.0 International license.

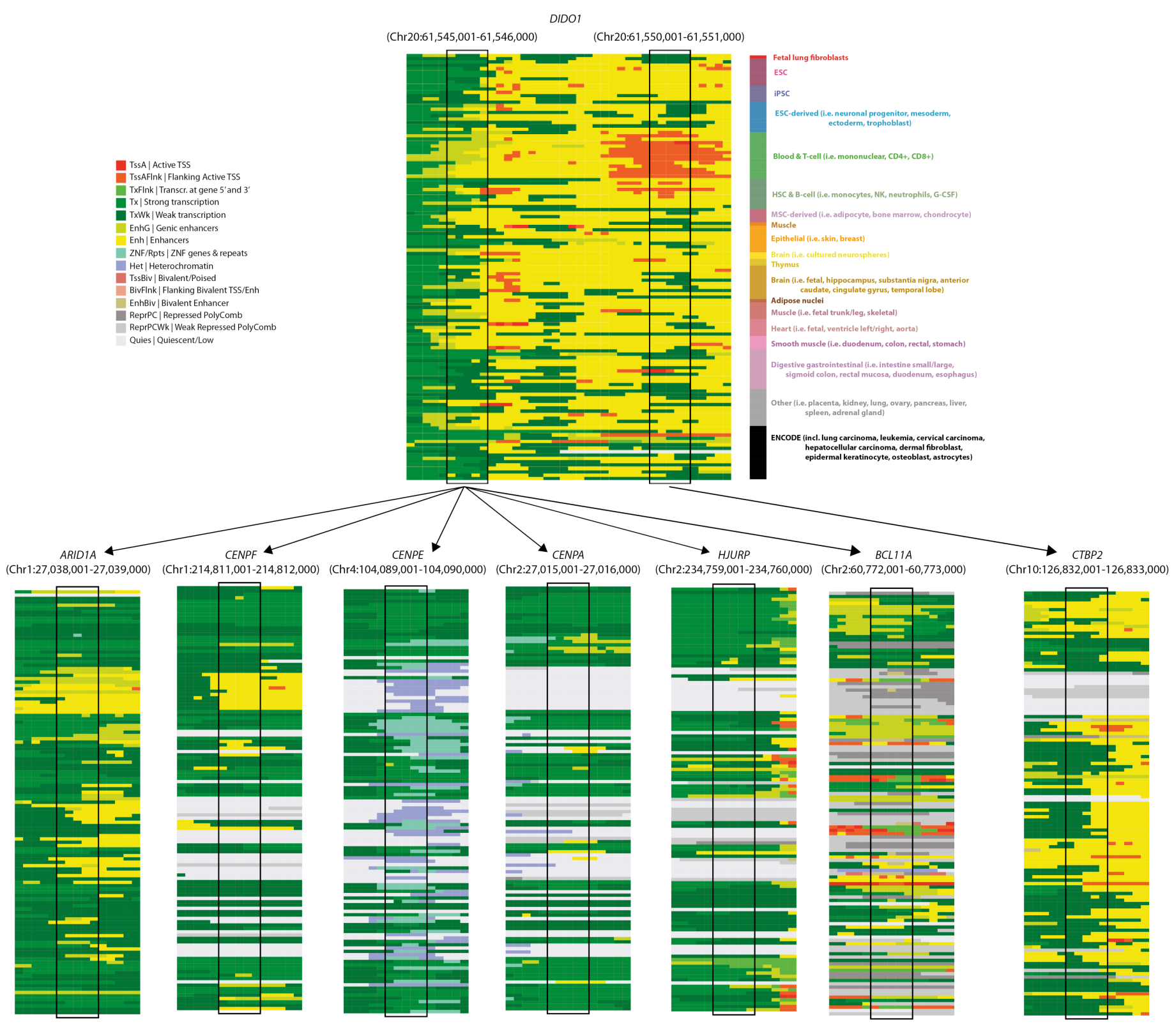

Figure 5 
bioRxiv preprint doi: https://doi.org/10.1101/2021.09.27.462041; this version posted September 29, 2021. The copyright holder for this

preprint (which was not certified by peer review) is the author/funder, who has granted bioRxiv a license to display the preprint in perpetuity. It is made available under aCC-BY-NC-ND 4.0 International license.

A
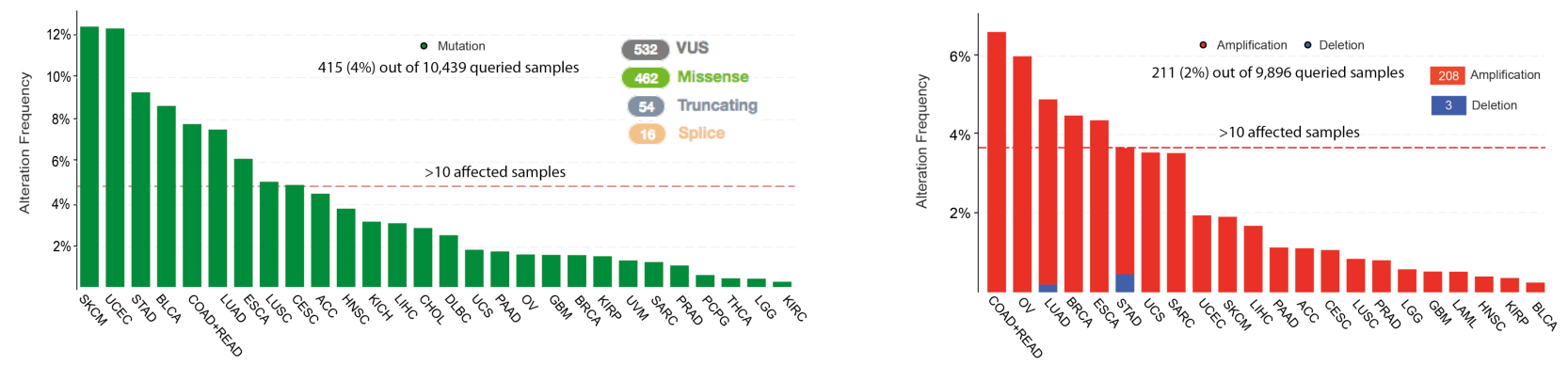

B

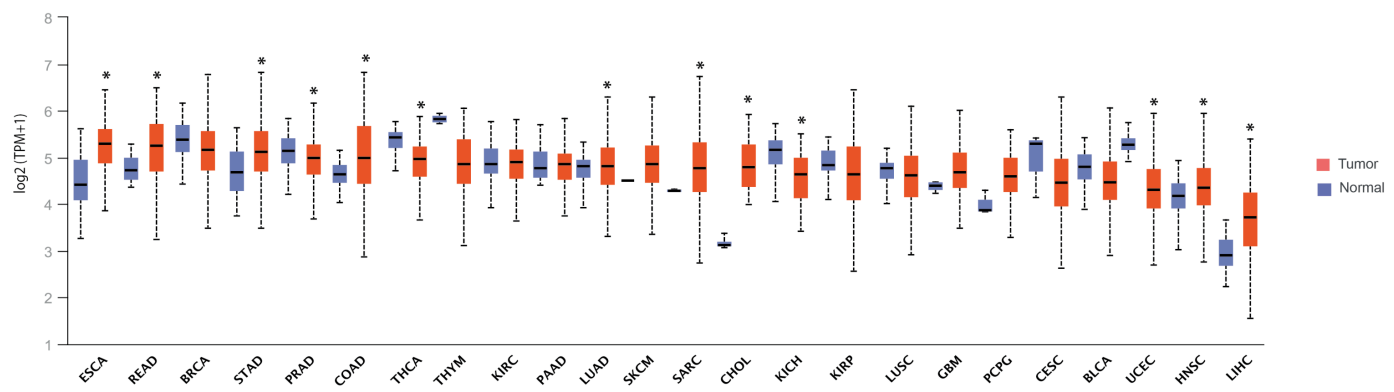

C

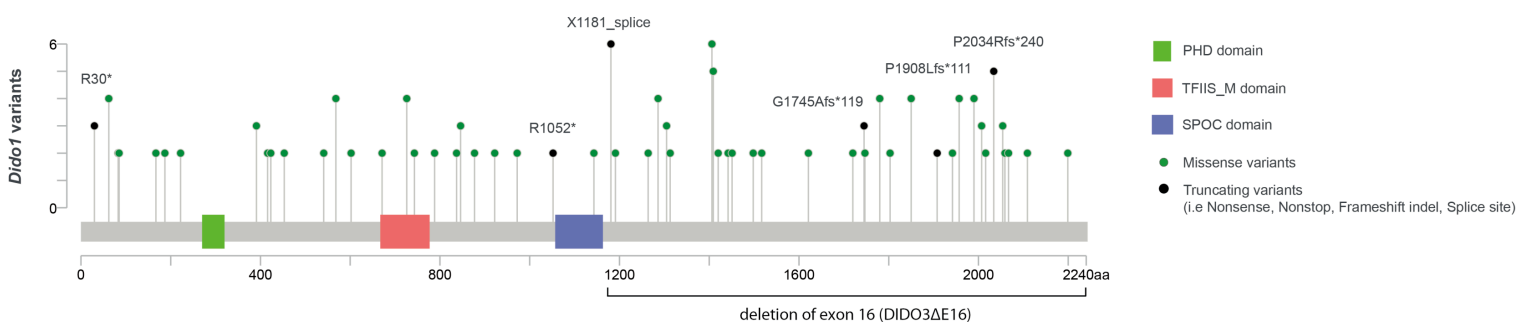

D

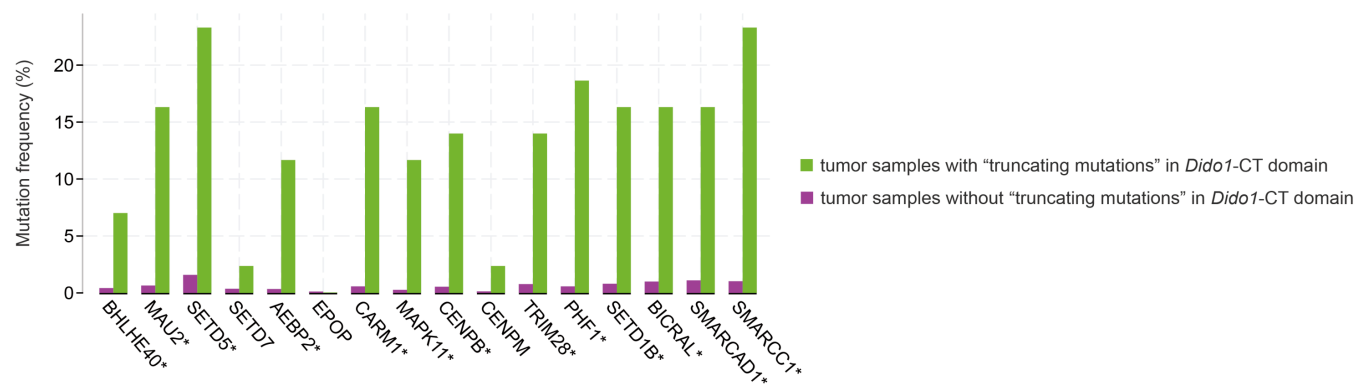

Figure 6 


\section{Supplementary Table and Files}

Supplementary Table S1. Genes with expression changes between DID03DE16 and WT ESC, and putative DID03 interactions in large protein complexes

(a) Gene position is represented by chromosome (Chr) number and strand directions in parenthesis (forward (+) and reverse $(-)$ ); (b) Unique MACS2 identifiers of ChIP-seq peak according to the HA-DID03 dataset (GSE85029); (c) Gene expression changes, $\log 2$ fold change $\left(\log _{2} \mathrm{FC}\right)$ and adjusted p-values (FDR) between DID03 $\triangle \mathrm{E} 16$ and WT ESC, were calculated from RNAseq data in edgeR. (d) UniProtKB annotations (www.uniprot.org). Hyphens (-) indicate that ChIP-seq peaks or gene expression changes were not detected.

Supplementary Table S2. DID03 binding sites intersection with RNAPII, CTCF, Polycomb, and H3 modifications

(a) Query ChIP-seq sample, (b) Target ChIP-seq sample, (c) Number of query peaks, (d) Number of target peaks, (e) Number of overlapped peaks between query and target, (f) Percentage of overlapped peaks, (g) the genomic region analysed, (h) calculated p-value by ChIPseeker, (i) p-value correction (FDR) according to the Benjamini and Hochberg method. The values were obtained using the ChIPseeker command enrichPeakOverlap(queryPeak=file1, targetPeak=file-list, TxDb= TxDb.Mmusculus.UCSC.mm10.knownGene, pAdjustMethod="BH", nShuffle=10000, chainFile=NULL, verbose=FALSE) and a number of randomly permutations in the genomic locations of 10000.+++ Overlap more than expected (Boferroni corrected p-value < 0.001). ++ Overlap more than expected (Boferroni corrected p-value $<0.01$ ) + Overlap more than expected (Boferroni corrected p-value < 0.05). --- Overlap less than expected (Boferroni corrected p-value $<0.001$ ). -- Overlap less than expected (Boferroni corrected p-value $<0.01$ ). - Overlap less than expected (Boferroni corrected $p$-value $<0.05$ ). NS nonsignificant overlap.

\section{Supplementary Table S3. Correlated genomic regions identified by Epicorr v1.20}

(a) Genomic regions are represented by chromosome number and start-end positions; (b) Epicorr v1.20 correlation score above 0.7; (c) UniProtKB annotations (www.uniprot.org). (d) Chromatin states that overlap in the two correlated regions. Acronyms: enhancers (Enh); genic enhancers (EnhG); strong transcription (Tx); weak transcription (TxWk).

\section{Supplementary Table S4. List of cancer types, number of tumor and normal samples, and statistical significance in the gene expression}

The statistical significance (P-values) of normal-vs-tumour differences in gene expression levels was estimated by Student's ttest according to the UALCAN web-portal (http://ualcan.path.uab.edu). Significantly different TPM values $(\mathrm{P}<0.001)$ were highlighted in bold.

\section{Supplementary File 1. Summary of the RNA-seq analysis}

\section{Supplementary File 2. ChIPseeker annotations for the DID03 ChIP-seq dataset}

\section{Supplementary File 3. Gene Ontology enrichment analysis for the genes within the correlated regions identify by Epicorr v1.20}

Supplementary File 4. Dido1 genomic alterations annotated in TCGA-PanCancer Atlas studies 
bioRxiv preprint doi: https://doi.org/10.1101/2021.09.27.462041; this version posted September 29, 2021. The copyright holder for this preprint (which was not certified by peer review) is the author/funder, who has granted bioRxiv a license to display the preprint in perpetuity. It is made available under aCC-BY-NC-ND 4.0 International license.

Supplementary Table S1

\begin{tabular}{|c|c|c|c|c|}
\hline Gene & Chr (a) & ChIP-seq (b) & RNA-seq (c) & Description (d) \\
\hline \multicolumn{5}{|c|}{ Primary target gene } \\
\hline Jade1 & $\operatorname{Chr} 3(+)$ & \#1708 to \#1713 & $\begin{array}{l}\log _{2} \mathrm{FC}=-5.91 \\
\mathrm{FDR}=2.74 \mathrm{e}-04\end{array}$ & $\begin{array}{l}\text { Histone acetylation (H4K5ac, H4K8ac, H4K12ac), } \\
\text { HBO1 complex }\end{array}$ \\
\hline$W d r 33$ & Chr18 (+) & \#1300 & $\begin{array}{l}\log _{2} \mathrm{FC}=0.96 \\
\mathrm{FDR}=6.47 \mathrm{e}-04\end{array}$ & RNA pol II associated (mRNA 3'-end processing) \\
\hline Dhx16 & Chr17 (+) & \#1220, \#2021 & $\begin{array}{l}\log _{2} \mathrm{FC}=-1.07 \\
\mathrm{FDR}=6.49 \mathrm{e}-04\end{array}$ & mRNA splicing \\
\hline$M b d 3$ & Chr10 (-) & \#226, \#227, \#228 & $\begin{array}{l}\log _{2} \mathrm{FC}=0.81 \\
\mathrm{FDR}=1.02 \mathrm{e}-03\end{array}$ & Methyl-CpG-binding domain protein \\
\hline Pus3 & Chr9 (+) & \#2744, \#2745, \#2746 & $\begin{array}{l}\log _{2} \mathrm{FC}=3.94 \\
\mathrm{FDR}=2.3 \mathrm{e}-09\end{array}$ & tRNA pseudouridine synthase \\
\hline Klf2 & Chr8 (+) & \#2656, \#2657 & $\begin{array}{l}\log _{2} \mathrm{FC}=0.7 \\
\mathrm{FDR}=2.95 \mathrm{e}-03\end{array}$ & RNA pol II associated (transcription factor) \\
\hline Sall1 & Chr8 (-) & \#2682 & $\begin{array}{l}\log _{2} \mathrm{FC}=-1.13 \\
\mathrm{FDR}=6.27 \mathrm{e}-04\end{array}$ & $\begin{array}{l}\text { Transcription repressor (pluripotency and } \\
\text { differentiation }\end{array}$ \\
\hline \multicolumn{5}{|c|}{ Secondary target gene (downstream) } \\
\hline Suv420h1/Kmt5b & Chr19 (+) & - & $\begin{array}{l}\log _{2} \mathrm{FC}=-2.2 \\
\mathrm{FDR}=9.52 \mathrm{e}-06\end{array}$ & Histone methyltransferase (H4K20me2/3) \\
\hline Foxd3 & Chr4 (+) & - & $\begin{array}{l}\log _{2} \mathrm{FC}=1.5 \\
\mathrm{FDR}=1.85 \mathrm{e}-05\end{array}$ & Maintenance of pluripotent cells \\
\hline Otx2 & Chr14 (-) & - & $\begin{array}{l}\log _{2} \mathrm{FC}=-2.16 \\
\mathrm{FDR}=2.76 \mathrm{e}-03\end{array}$ & Differentiation associated gene \\
\hline Sugp1 & Chr8 (+) & - & $\begin{array}{l}\log _{2} \mathrm{FC}=-1.07 \\
\mathrm{FDR}=2.46 \mathrm{e}-02\end{array}$ & mRNA splicing \\
\hline Foxj2 & Chr6 (+) & - & $\begin{array}{l}\log _{2} \mathrm{FC}=-0.99 \\
\mathrm{FDR}=4.85 \mathrm{e}-02\end{array}$ & Transcription coactivator \\
\hline Zfp 462 & Chr4 (+) & - & $\begin{array}{l}\log _{2} \mathrm{FC}=-0.82 \\
\mathrm{FDR}=1.94 \mathrm{e}-02\end{array}$ & (pluripotency and differentiation) \\
\hline \multicolumn{5}{|c|}{ Putative DIDO3 interactions in large protein complexes } \\
\hline Nanog & Chr6 (+) & $\# 2269$ & & Transcription factor (pluripotency) \\
\hline Rpa2 & Chr4 (+) & $\# 1925$ & - & Replication protein A complex \\
\hline Suv39h1 & $\operatorname{ChrX}(-)$ & $\# 2850$ & - & $\begin{array}{l}\text { Histone methyltransferase }(\mathrm{H} 3 \mathrm{~K} 9 \mathrm{me} 2 / 3) \text {, } \\
\text { constitutive heterochromatin at pericentromeric }\end{array}$ \\
\hline Trrap & Chr5 (+) & \#2186 & - & $\begin{array}{l}\text { NuA4 histone acetyltransferase complex (H2A, } \\
\text { H4). SWR1-like complex (remove H2A.Z/H2AZ1) }\end{array}$ \\
\hline Ep400 & Chr5 (-) & \#2124 & - & $\begin{array}{l}\text { NuA4 histone acetyltransferase complex (H2A, } \\
\text { H4). SWR1-like complex (remove H2A.Z/H2AZ1) }\end{array}$ \\
\hline Tet1 & Chr10 (-) & \#194, \#195, \#196 & - & Promote histone H2B GlcNAcylation \\
\hline Npm1 & Chr11 (-) & \#355, \#356, \#357 & - & $\begin{array}{l}\text { Involved in histone assembly and centrosome } \\
\text { duplication }\end{array}$ \\
\hline$C d k 12$ & Chr11 (+) & \#521, \#522, \#523 & - & $\begin{array}{l}\text { Phosphorylates RNAPII CTD, transcription } \\
\text { elongation }\end{array}$ \\
\hline $\operatorname{Dh} \times 9$ & Chr1 (-) & \#122, \#123 & - & $\begin{array}{l}\text { Unwinds R-loops; Binds dsDNA, ssDNA, dsRNA, } \\
\text { ssRNA and poly(A)-containing RNA }\end{array}$ \\
\hline Dhx30 & Chr9 (-) & $\# 2837$ & - & RNA-dependent helicase \\
\hline$D d x 39 b$ & Chr17 (+) & $\# 1214$ & - & $\begin{array}{l}\text { Cotranscriptional and nonscheduled R-loop } \\
\text { removal }\end{array}$ \\
\hline Setx & Chr2 (+) & \#1482 & - & $\begin{array}{l}\text { Modulate RNAPII binding to chromatin. R-loop } \\
\text { resolution at G-rich pause sites }\end{array}$ \\
\hline Sirt3 & Chr7 (-) & \#2566, \#2567 & - & $\begin{array}{l}\text { NAD+-dependent deacetylase. Involved in } \\
\text { stabilizing heterochromatin and senescence }\end{array}$ \\
\hline Paf1 & Chr7 (+) & \#2381 & - & $\begin{array}{l}\text { PAF1 complex. Modulate RNAPII elongation rates } \\
\text { and ESC pluripotency }\end{array}$ \\
\hline Cpsf4 & Chr5 (+) & \#2187, \#2188 & - & CPSF complex (pre-mRNA 3'-end formation) \\
\hline Cpsf6 & Chr10 (-) & $\begin{array}{l}\# 282, \# 283, \# 284, \\
\# 285\end{array}$ & - & $\begin{array}{l}\text { CFIm complex (pre-mRNA 3'-end cleavage and } \\
\text { polyadenylation) }\end{array}$ \\
\hline Pabpc1 & Chr15 (-) & \#924 & - & $\begin{array}{l}\text { Binds the poly(A) tail of mRNA (pre-mRNA } \\
\text { splicing and mRNA stability) }\end{array}$ \\
\hline Pabpn1 & Chr14 (+) & \#854, \#855 & - & $\begin{array}{l}\text { Involved in the } 3 \text { '-end formation of mRNA } \\
\text { precursors. Stimulates poly }(\mathrm{A}) \text { polymerase }\end{array}$ \\
\hline Pnrc2 & Chr4 (-) & \#1945, \#1946, \#1947 & - & Involved in nonsense-mediated mRNA decay \\
\hline$S f p q$ & Chr4 (+) & \#1903, \#1904, \#1905 & - & mRNA splicing \\
\hline Smg5 & Chr3 (+) & $\# 1744$ & - & Involved in nonsense-mediated mRNA decay \\
\hline Upf1 & Chr8 (-) & \#2631 & - & $\begin{array}{l}\text { RNA-dependent helicase (nonsense-mediated } \\
\text { decay of mRNAs containing premature stop } \\
\text { codons) }\end{array}$ \\
\hline Zc3h12 & Chr4 (-) & \#1901 & - & $\begin{array}{l}\text { Endoribonuclease (mRNA decay). Cleaves mRNA } \\
\text { harboring a stem-loop located in their 3'-UTRs. }\end{array}$ \\
\hline
\end{tabular}


bioRxiv preprint doi: https://doi.org/10.1101/2021.09.27.462041; this version posted September 29, 2021. The copyright holder for this preprint (which was not certified by peer review) is the author/funder, who has granted bioRxiv a license to display the preprint in perpetuity. It is made available under aCC-BY-NC-ND 4.0 International license.

Supplementary Table S2

\begin{tabular}{|c|c|c|c|c|c|c|c|}
\hline \multicolumn{8}{|c|}{ PyRanges } \\
\hline qSample(a) & tSample(b) & qLen(c) & tLen(d) & Overlap (\%)(e)(f) & All(g) & Promoters(g) & Intergenic(g) \\
\hline DID03 & RNAPII & 2888 & 29041 & $2269(78.6 \%)$ & +++ & +++ & +++ \\
\hline DID03 & H3K36me3 & 2888 & 33970 & $2002(69.3 \%)$ & +++ & +++ & +++ \\
\hline DIDO3 & H3K27ac & 2888 & 29284 & $1036(35.9 \%)$ & +++ & +++ & +++ \\
\hline DID03 & H3K4me3 & 2888 & 43051 & $811(28.1 \%)$ & +++ & +++ & +++ \\
\hline DID03 & CTCF & 2888 & 49203 & $360(12.5 \%)$ & +++ & +++ & +++ \\
\hline DID03 & PRC2 & 2888 & 23646 & $242(8.4 \%)$ & +++ & +++ & NS \\
\hline DID03 & RING1B & 2888 & 10116 & $41(1.4 \%)$ & NS & +++ & $-\cdots$ \\
\hline DID03 & H3K27me3 & 2888 & 19812 & $22(0.8 \%)$ & --- & NS & --- \\
\hline RNAPII & H3K36me3 & 29041 & 33970 & $16326(56.2 \%)$ & +++ & +++ & --- \\
\hline RNAPII & H3K27ac & 29041 & 29284 & $14402(49.6 \%)$ & +++ & +++ & +++ \\
\hline RNAPII & H3K4me3 & 29041 & 43051 & $16511(56.9 \%)$ & +++ & +++ & +++ \\
\hline RNAPII & CTCF & 29041 & 49203 & $7174(24.7 \%)$ & +++ & +++ & --- \\
\hline RNAPII & PRC2 & 29041 & 23646 & 3385 (11.7\%) & +++ & +++ & --- \\
\hline RNAPII & RING1B & 29041 & 10116 & $3871(13.3 \%)$ & +++ & +++ & --- \\
\hline RNAPII & H3K27me3 & 29041 & 19812 & $2310(8.0 \%)$ & +++ & +++ & --- \\
\hline H3K36me3 & H3K27ac & 33970 & 29284 & $8067(23.7 \%)$ & +++ & +++ & --- \\
\hline H3K36me3 & H3K4me3 & 33970 & 43051 & $9286(27.3 \%)$ & +++ & +++ & --- \\
\hline H3K36me3 & CTCF & 33970 & 49203 & $6792(20.0 \%)$ & +++ & +++ & --- \\
\hline H3K36me3 & PRC2 & 33970 & 23646 & 1557 (4.6\%) & --- & +++ & --- \\
\hline H3K36me3 & RING1B & 33970 & 10116 & $611(1.8 \%)$ & --- & NS & --- \\
\hline H3K36me3 & H3K27me3 & 33970 & 19812 & $449(1.3 \%)$ & --- & $-\cdots$ & --- \\
\hline H3K4me3 & H3K27ac & 43051 & 29284 & $18893(43.9 \%)$ & +++ & +++ & +++ \\
\hline H3K4me3 & CTCF & 43051 & 49203 & $11714(27.2 \%)$ & +++ & +++ & +++ \\
\hline H3K4me3 & PRC2 & 43051 & 23646 & $10043(23.3 \%)$ & +++ & +++ & +++ \\
\hline H3K4me3 & RING1B & 43051 & 10116 & $10236(23.8 \%)$ & +++ & +++ & +++ \\
\hline H3K4me3 & H3K27me3 & 43051 & 19812 & $9754(22.7 \%)$ & +++ & +++ & +++ \\
\hline H3K27ac & CTCF & 29284 & 49203 & $6848(23.4 \%)$ & +++ & +++ & +++ \\
\hline H3K27ac & PRC2 & 29284 & 23646 & $2368(8.1 \%)$ & +++ & +++ & --- \\
\hline H3K27ac & RING1B & 29284 & 10116 & $2636(9.0 \%)$ & +++ & +++ & NS \\
\hline H3K27ac & H3K27me3 & 29284 & 19812 & $1121(3.8 \%)$ & NS & +++ & --- \\
\hline CTCF & PRC2 & 49203 & 23646 & $3671(7.5 \%)$ & +++ & +++ & +++ \\
\hline CTCF & RING1B & 49203 & 10116 & $3574(7.3 \%)$ & +++ & +++ & +++ \\
\hline CTCF & H3K27me3 & 49203 & 19812 & $4279(8.7 \%)$ & +++ & +++ & +++ \\
\hline PRC2 & RING1B & 23646 & 10116 & $7638(32.3 \%)$ & +++ & +++ & +++ \\
\hline PRC2 & H3K27me3 & 23646 & 19812 & 8009 (33.9\%) & +++ & +++ & +++ \\
\hline RING1B & H3K27me3 & 10116 & 19812 & $7142(70.6 \%)$ & +++ & +++ & +++ \\
\hline \multicolumn{8}{|c|}{ ChIPseeker } \\
\hline qSample (a) & tSample(b) & qLen(c) & $\operatorname{tLen}(d)$ & N_OL(e) & N_OL (\%qLen)(f) & p-value (h) & p-adjust ${ }^{(i)}$ \\
\hline HA-DIDO3 & RNAPII & 2888 & 29041 & 2290 & $79.3 \%$ & $9.9 \mathrm{e}-05$ & $1.6 \mathrm{e}-04$ \\
\hline HA-DID03 & H3K36me3 & 2888 & 33970 & 2019 & \multirow{2}{*}{$\begin{array}{l}69.9 \% \\
36.4 \%\end{array}$} & $9.9 e-05$ & $1.6 \mathrm{e}-04$ \\
\hline HA-DIDO3 & H3K27ac & 2888 & 29284 & 1050 & & $9.9 \mathrm{e}-05$ & $1.6 \mathrm{e}-04$ \\
\hline HA-DID03 & H3K4me3 & 2888 & 43051 & 829 & $28.7 \%$ & $9.9 \mathrm{e}-05$ & $1.6 \mathrm{e}-04$ \\
\hline HA-DIDO3 & CTCF & 2888 & 49203 & 368 & $12.7 \%$ & $4.6 \mathrm{e}-03$ & $6.9 \mathrm{e}-03$ \\
\hline HA-DIDO3 & PRC2 & 2888 & 23646 & 287 & $9.9 \%$ & $9.9 \mathrm{e}-05$ & $1.6 \mathrm{e}-04$ \\
\hline HA-DIDO3 & RING1B & 2888 & 10116 & 41 & $1.4 \%$ & 0.2 & 0.2 \\
\hline HA-DIDO3 & H3K27me3 & 2888 & 19812 & 22 & $0.8 \%$ & 0.9 & 0.9 \\
\hline
\end{tabular}


bioRxiv preprint doi: https://doi.org/10.1101/2021.09.27.462041; this version posted September 29, 2021. The copyright holder for this preprint (which was not certified by peer review) is the author/funder, who has granted bioRxiv a license to display the preprint in perpetuity. It is made available under aCC-BY-NC-ND 4.0 International license.

\section{Supplementary Table S3}

\begin{tabular}{|c|c|c|c|c|c|}
\hline Region1 (a) & Gene & Region2 (Dido1) (a) & Score ${ }^{(b)}$ & Description (c) & Chromatin states (d) \\
\hline $1: 27,038,001-27,039,000$ & ARID1A & $20: 61,545,001-61,546,000$ & 0.782 & $\begin{array}{l}\text { SWI/SNF complex, } \\
\text { chromatin remodeling }\end{array}$ & Enh, EnhG, Tx, TxWk \\
\hline $2: 60,772,001-60,773,000$ & $B C L 11 A$ & $20: 61,545,001-61,546,000$ & 0.8 & $\begin{array}{l}\text { TF associated with the } \\
\text { SWI/SNF complex }\end{array}$ & Tx, TxWk \\
\hline $2: 27,015,001-27,016,000$ & CENPA & $20: 61,545,001-61,546,000$ & 0.704 & $\begin{array}{l}\text { Centromere-associated } \\
\text { protein network }\end{array}$ & Tx, TxWk \\
\hline $4: 104,089,001-104,090,000$ & CENPE & $20: 61,545,001-61,546,000$ & 0.726 & $\begin{array}{l}\text { Centromere-associated } \\
\text { protein network }\end{array}$ & Tx, TxWk \\
\hline 1:214,811,001-214,812,000 & CENPF & $20: 61,545,001-61,546,000$ & 0.809 & $\begin{array}{l}\text { Centromere-associated } \\
\text { protein network }\end{array}$ & Enh, Tx, TxWk \\
\hline $1: 214,814,001-214,815,000$ & CENPF & $20: 61,545,001-61,546,000$ & 0.778 & $\begin{array}{l}\text { Centromere-associated } \\
\text { protein network }\end{array}$ & Tx, TxWk \\
\hline 1:214,812,001-214,813,000 & CENPF & $20: 61,545,001-61,546,000$ & 0.742 & $\begin{array}{l}\text { Centromere-associated } \\
\text { protein network }\end{array}$ & Enh, Tx, TxWk \\
\hline $1: 214,805,001-214,806,000$ & CENPF & $20: 61,545,001-61,546,000$ & 0.734 & $\begin{array}{l}\text { Centromere-associated } \\
\text { protein network }\end{array}$ & Enh, Tx, TxWk \\
\hline $1: 214,819,001-214,820,000$ & CENPF & $20: 61,545,001-61,546,000$ & 0.729 & $\begin{array}{l}\text { Centromere-associated } \\
\text { protein network }\end{array}$ & Tx, TxWk \\
\hline $2: 234,759,001-234,760,000$ & HJURP & $20: 61,545,001-61,546,000$ & 0.708 & $\begin{array}{l}\text { H3 chaperone complex } \\
\text { of CENP-A variant }\end{array}$ & Tx, TxWk \\
\hline $2: 234,747,001-234,748,000$ & HJURP & $20: 61,545,001-61,546,000$ & 0.704 & $\begin{array}{l}\text { H3 chaperone complex } \\
\text { of CENP-A variant }\end{array}$ & EnhG, Tx, TxWk \\
\hline $10: 126,832,001-126,833,000$ & СТВР2 & $20: 61,550,001-61,551,000$ & 0.857 & $\begin{array}{l}\text { Polycomb accessory } \\
\text { protein (PRC2) }\end{array}$ & Enh, TxWk \\
\hline $10: 126,820,001-126,821,000$ & СТВР2 & $20: 61,550,001-61,551,000$ & 0.743 & $\begin{array}{l}\text { Polycomb accessory } \\
\text { protein (PRC2) }\end{array}$ & Enh, TxWk \\
\hline
\end{tabular}


bioRxiv preprint doi: https://doi.org/10.1101/2021.09.27.462041; this version posted September 29, 2021. The copyright holder for this preprint (which was not certified by peer review) is the author/funder, who has granted bioRxiv a license to display the preprint in perpetuity. It is made available under aCC-BY-NC-ND 4.0 International license.

\section{Supplementary Table S4}

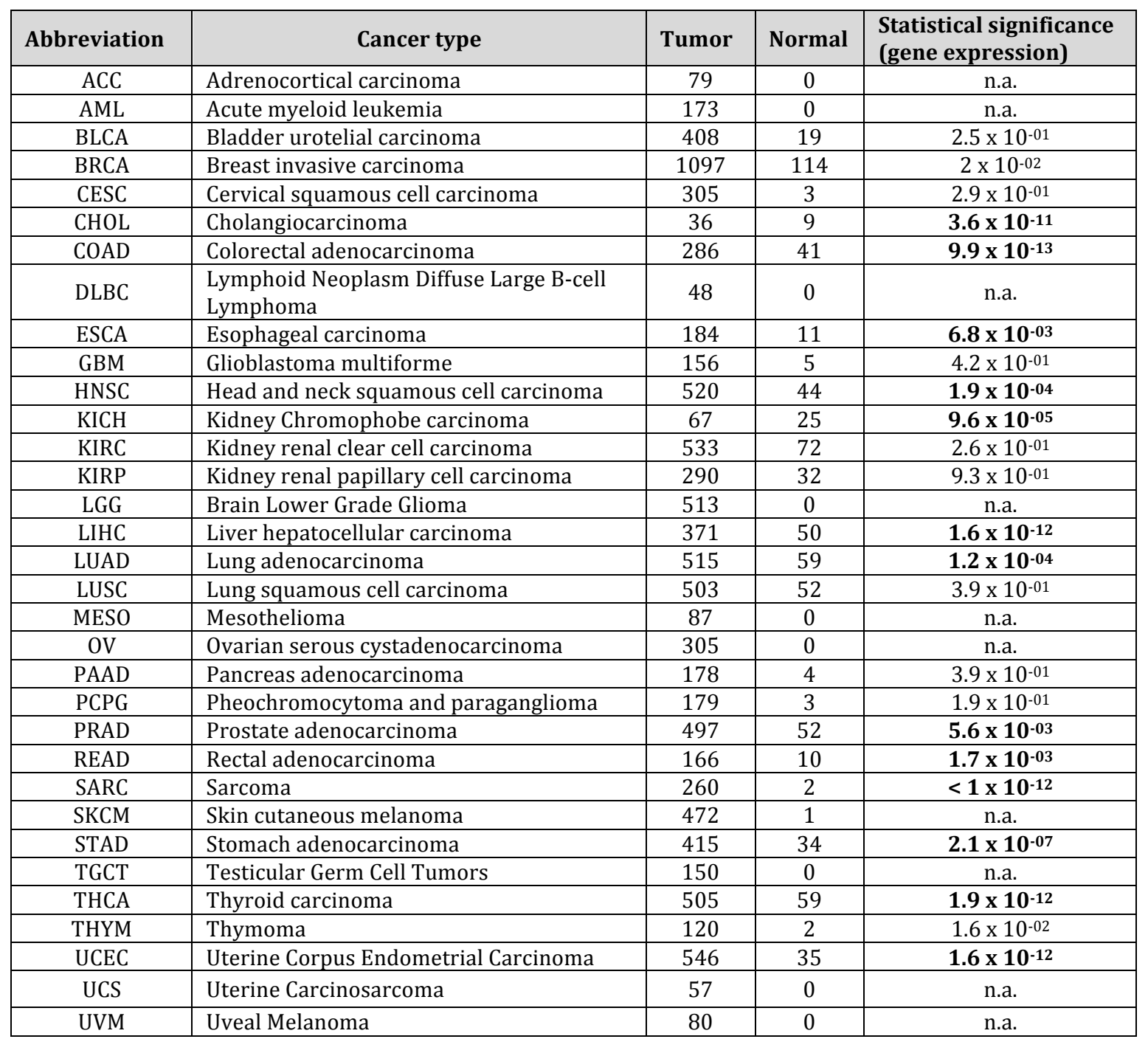

